A. Wagner

Residual demand modeling and application to electricity pricing 
(C) Fraunhofer-Institut für Techno- und Wirtschaftsmathematik ITWM 2012

ISSN 1434-9973

Bericht 213 (2012)

Alle Rechte vorbehalten. Ohne ausdrückliche schriftliche Genehmigung des Herausgebers ist es nicht gestattet, das Buch oder Teile daraus in irgendeiner Form durch Fotokopie, Mikrofilm oder andere Verfahren zu reproduzieren oder in eine für Maschinen, insbesondere Datenverarbeitungsanlagen, verwendbare Sprache zu übertragen. Dasselbe gilt für das Recht der öffentlichen Wiedergabe.

Warennamen werden ohne Gewährleistung der freien Verwendbarkeit benutzt.

Die Veröffentlichungen in der Berichtsreihe des Fraunhofer ITWM können bezogen werden über:

Fraunhofer-Institut für Techno- und Wirtschaftsmathematik ITWM Fraunhofer-Platz 1

67663 Kaiserslautern

Germany

Telefon: $\quad+49(0) 631 / 31600-4674$

Telefax: $\quad+49(0) 631 / 31600-5674$

E-Mail: presse@itwm.fraunhofer.de

Internet: www.itwm.fraunhofer.de 
Das Tätigkeitsfeld des Fraunhofer-Instituts für Techno- und Wirtschaftsmathematik ITWM umfasst anwendungsnahe Grundlagenforschung, angewandte Forschung sowie Beratung und kundenspezifische Lösungen auf allen Gebieten, die für Techno- und Wirtschaftsmathematik bedeutsam sind.

In der Reihe »Berichte des Fraunhofer ITWM « soll die Arbeit des Instituts kontinuierlich einer interessierten Öffentlichkeit in Industrie, Wirtschaft und Wissenschaft vorgestellt werden. Durch die enge Verzahnung mit dem Fachbereich Mathematik der Universität Kaiserslautern sowie durch zahlreiche Kooperationen mit internationalen Institutionen und Hochschulen in den Bereichen Ausbildung und Forschung ist ein großes Potenzial für Forschungsberichte vorhanden. In die Berichtreihe werden sowohl hervorragende Diplom- und Projektarbeiten und Dissertationen als auch Forschungsberichte der Institutsmitarbeiter und Institutsgäste zu aktuellen Fragen der Techno- und Wirtschaftsmathematik aufgenommen.

Darüber hinaus bietet die Reihe ein Forum für die Berichterstattung über die zahlreichen Kooperationsprojekte des Instituts mit Partnern aus Industrie und Wirtschaft.

Berichterstattung heißt hier Dokumentation des Transfers aktueller Ergebnisse aus mathematischer Forschungs- und Entwicklungsarbeit in industrielle Anwendungen und Softwareprodukte - und umgekehrt, denn Probleme der Praxis generieren neue interessante mathematische Fragestellungen.

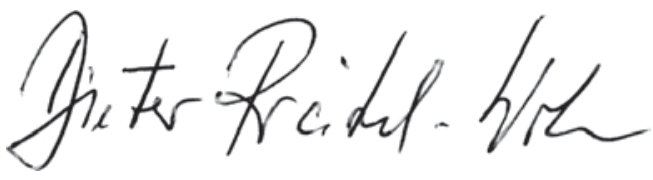

Prof. Dr. Dieter Prätzel-Wolters Institutsleiter

Kaiserslautern, im Juni 2001 



\title{
Residual Demand Modeling and Application to Electricity Pricing
}

\author{
Andreas Wagner* \\ 9th March 2012 \\ Fraunhofer ITWM \\ Department for Financial Mathematics \\ Fraunhofer-Platz 1 \\ 67663 Kaiserslautern \\ Germany \\ andreas.wagner@itwm.fraunhofer.de
}

\begin{abstract}
Worldwide the installed capacity of renewable technologies for electricity production is rising tremendously. The German market is particularly progressive and its regulatory rules imply that production from renewables is decoupled from market prices and electricity demand. Conventional generation technologies are to cover the residual demand (defined as total demand minus production from renewables) but set the price at the exchange. Existing electricity price models do not account for the new risks introduced by the volatile production of renewables and their effects on the conventional demand curve. A model for residual demand is proposed, which is used as an extension of supply/demand electricity price models to account for renewable infeed in the market. Infeed from wind and solar (photovoltaics) is modeled explicitly and withdrawn from total demand. The methodology separates the impact of weather and capacity. Efficiency is transformed on the real line using the logit-transformation and modeled as a stochastic process. Installed capacity is assumed a deterministic function of time. In a case study the residual demand model is applied to the German day-ahead market using a supply/demand model with a deterministic supply-side representation. Price trajectories are simulated and the results are compared to market future and option prices. The trajectories show typical features seen in market prices in recent years and the model is able to closely reproduce the structure and magnitude of market prices. Using the simulated prices it is found that renewable infeed increases the volatility of forward prices in times of low demand, but can reduce volatility in peak hours. Prices for different scenarios of installed wind and solar capacity are compared and the meritorder effect of increased wind and solar capacity is calculated. It is found that wind has a stronger overall effect than solar, but both are even in peak hours.
\end{abstract}

Keywords: residual demand modeling, renewable infeed, wind infeed, solar infeed, electricity demand, German power market, merit-order effect

\footnotetext{
${ }^{*}$ The author is grateful for the financial support received from the Innovation Center Applied System Modeling.
} 


\section{Introduction}

Modeling electricity demand is important for every utility taking part in the electricity sector, either as producer, retailer or trader on the financial markets for electricity. In some applications one is interested in an exact load forecast on different time scales and spatial resolutions. The shortterm load forecast models are mainly based on weather forecasts, whereas long-term models include growth of the economy, progression in energy-saving technologies, population growth, etc. On the other hand financial modeling of electricity prices (for derivative pricing, risk-management or investment planning) requires that the distribution of the demand model is close to reality. In this paper we are concerned with the role of demand modeling in electricity price models, which implies that we look at demand prevailing at the whole market in question. Electricity price models, which use demand as a state variable are known as supply/demand models (or hybrid models or equilibrium models). In this class of models, the supply side (electricity production) and the demand side (electricity consumption) are described separately. The market price is determined by the marginal production unit in the merit order needed to match demand. All models in the literature use demand as a state variable, which is the only one in the early work by Barlow (2002). More recent approaches further include capacity (cf. Cartea \& Villaplana 2008), fuel prices (cf. Pirrong \& Jermakyan 2008, Coulon \& Howison 2009, Smeers \& de Maere 2010, Carmona, Coulon \& Schwarz 2011) ${ }^{1}$, or both (cf. Aïd, Campi, Huu \& Touzi 2009, Aïd, Campi \& Langrené 2012) as state variables. Burger, Klar, Müller \& Schindlmayr (2004) also have a load dependent component in their model.

In recent years there has been a rapid growth in installed capacity of renewable energy sources (hydro, wind, solar ${ }^{2}$, biomass, geothermal), which is expected to continue for decades. Half of the worldwide newly added capacity in 2010 has been of renewable technologies (including hydro). Excluding hydro, the globally installed renewable capacity grew $25 \%$ over $2009^{3}$. In the European Union, renewables account for more than $40 \%$ of yearly capacity additions since $2005^{4}$. Due to strong political support, especially Germany already has a considerable high share of wind and solar power plants in its electricity system. By the end of 2011, Germany had 28 GW installed capacity of wind power plants and $20 \mathrm{GW}$ installed capacity of solar power plants, which together accounts for about $30 \%$ of total installed capacity ${ }^{5}$. In $2010,17 \%$ of German electricity consumption has been produced by renewable sources ${ }^{6}$, going up from $16.3 \%$ the year before despite a rise in demand of $4.3 \%{ }^{7}$. Scenarios ${ }^{8}$ for the year 2022 see renewable installed capacity in Germany between $93 \mathrm{GW}$ and $150 \mathrm{GW}$, which is (much) more than the German yearly peak demand (in 2010 at about $83 \mathrm{GW}$ ). In all those scenarios, conventional installed capacity is predicted to decrease to between $82 \mathrm{GW}$ and $92 \mathrm{GW}$.

This considerable amount of renewables sources in the system and the regulatory circumstances (see below) heavily influence the electricity price for Germany, which is traded at the EEX and EPEX. For example, the infeed from solar power plants changes the structure of the conventional demand profile significantly on a sunny day. This implies a change in the (intra-day) seasonality of market prices for electricity, as the seasonality in prices is mainly caused by the seasonality in demand.

In figure 1 the hourly production stack and the corresponding market prices are displayed. Supply is split in production from wind, production from solar and residual load. The prices follow the profile of residual load, which is covered by technologies other than wind and solar, i.e. mainly

\footnotetext{
${ }^{1}$ Pirrong \& Jermakyan (2008) and Smeers \& de Maere (2010) use a reflected load process in order to capture capacity constraints.

${ }^{2}$ In this paper we use the term solar for electricity production from solar energy. This technique is known as photovoltaics.

${ }^{3}$ Renewable Energy Policy Network for the 21st Century (2011)

${ }^{4}$ Figures available until 2010, Renewable Energy Policy Network for the 21st Century (2011).

${ }^{5}$ Own calculations based on data from European Energy Exchange AG (2012).

${ }^{6}$ Bundesministerium für Umwelt Naturschutz und Reaktorsicherheit (2011)

${ }^{7}$ Renewable Energy Policy Network for the 21st Century (2011)

${ }^{8} 50$ hertz, Amprion, EnBW Transportnetze AG \& TenneT TSO (2011)
} 

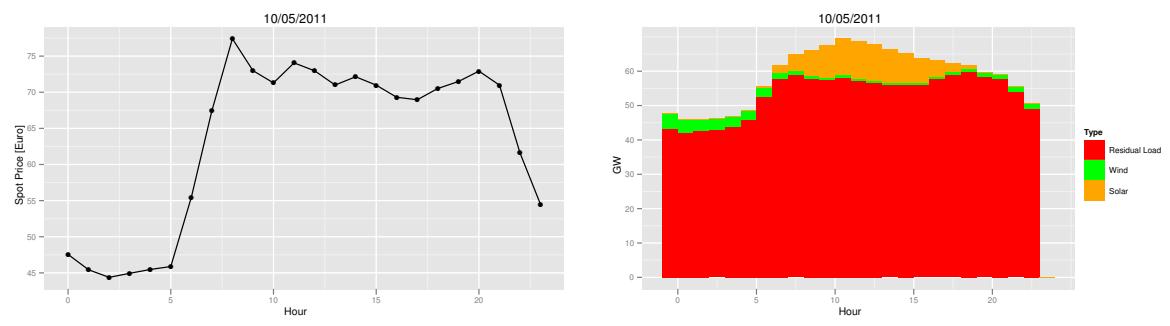

Figure 1: EPEX spot market prices and production profiles for Germany on a day with high renewable infeed.

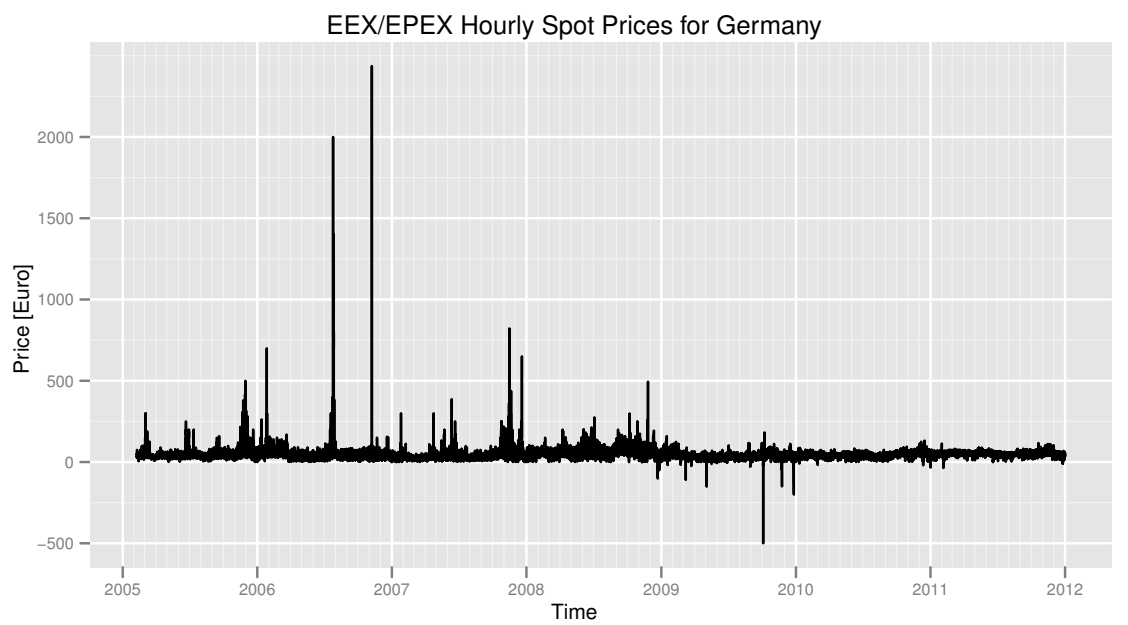

Figure 2: EEX/EPEX hourly spot prices from the year 2005 through 2011.

conventional generation units like nuclear, lignite, coal, and gas. We conclude that the intra-day price shape heavily depends on the amount of renewable infeed. This is not accounted for in existing demand side models in the literature.

The effect of renewable infeed is also seen in time-series of hourly spot prices. Figure 2 shows the hourly spot price at the EEX (since 2009 EPEX) from 2005 to 2011. There are less positive spikes since 2009 and they also reduced in magnitude. On the other hand, negative prices started to occur and especially in 2009 negative spikes are much more present than positive ones. In 2010 and 2011, the size of negative spikes reduced, indicating that producers are learning and trying to avoid negative prices (e.g. by assembling a more flexible power plant portfolio). The time series for 2011 in figure 3 reveals that there are still some moderate spikes in the market, both positive and negative. The typical situation in case of negative spikes is a very high renewable infeed (usually for a few hours only, caused by fluctuating wind infeed) on days with generally low demand (public holiday, weekend). The electricity oversupply during those hours is caused by baseload plants, which cannot be economically switched off for a few hours only (or are considered must-run plants for system stability). They are prepared to accept negative prices for a short time period in order to be able to continue with their production. Positive spikes occur usually in times of high conventional demand (so very expensive plants in the merit order have to be called to meet generation needs). As Germany has enough conventional capacity to meet peak demand even in times of zero renewable infeed (Bundesnetzagentur 2011b) the conventional capacity is near its limit only during times of low renewable infeed and high demand. An example is a cold winter day with low wind infeed and many snow covered solar panels. Further causes of positive spikes 


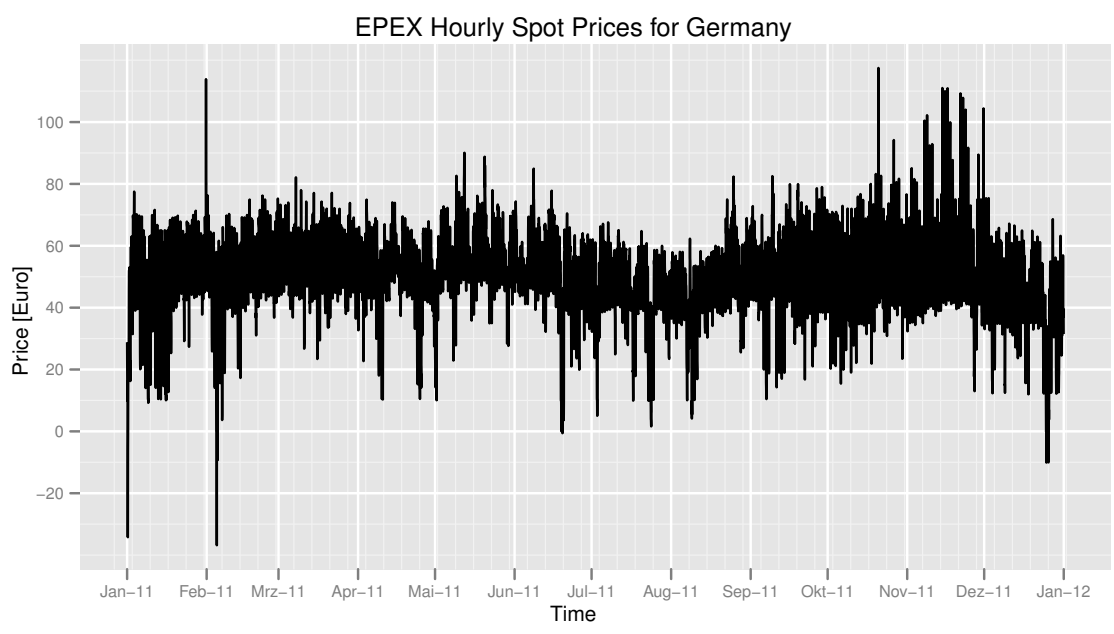

Figure 3: EPEX hourly spot prices for the year 2011.

are unexpected outages. In such a situation, the non-available plant has to meet its obligations by buying additional electricity from the exchange, which obviously drives the market price. If the non-available plant is part of a larger portfolio of plants, the owner is often able to balance the missing production within her portfolio, so the price peaks for a few hours only. The increasing share of solar infeed is reducing the risk for positive spikes. Solar produces mainly during hours of peak demand, so it reduces the conventional peakload. This is the so-called peak-shaving effect of solar, which is also visible in figure 1. A third characteristic of spot-prices seen in the figures is the seasonality on different time-scales. There is intra-day seasonality (figure 1), weekly seasonality (figure 3 ) and a yearly seasonality (figure 3 and 2).

Production from renewables introduces new uncertainty (=risk) to the market due to their volatile production profile. Therefore in order to apply supply/demand models on the German power market (or any other market with a high share of renewables in its system), the infeed from wind and solar power plants should be considered, especially as the seasonality in electricity prices is mainly generated by the seasonality in demand. In this work we propose an approach to explicitly include wind and solar infeed in a demand side model, which can be used to refine existing supply/demand models for electricity. Our work is based on the German power market, which is, as outlined above, very progressive in the integration of renewable power production.

The regulatory circumstances in Germany are based on the EEG ${ }^{9}$. It implies that all production from renewables must be fed into the electricity grid. Conventional generation units (nuclear, lignite, hard coal, gas, oil, pumped storage) are to cover the remaining demand only. As an incentive to investors, a guaranteed tariff for the produced electricity is paid for 20 years after the installation of the plant (feed-in tariff). We will model wind and solar only, as they have a particularly uncertain and fluctuating infeed profile (unlike hydro or biomass). As most of the wind and solar power plants have been build in recent years and therefore are eligible for the feed-in tariff and infeed priority, it is natural to consider the production from renewables as a demand reduction, i.e.

$$
\text { residual demand }=\text { (stochastic) total demand }- \text { (stochastic) infeed from renewables. }
$$

Residual (or conventional) demand is the electricity to be generated by conventional technologies. This is the demand which should be used in the merit order of conventional generation units to determine the market price (assuming a competitive market).

\footnotetext{
${ }^{9} \mathrm{EEG}$ is short for Erneuerbare-Energien-Gesetz (Renewable Energy Sources Act), see http://www. erneuerbare-energien.de for more information such as laws, statistics, etc.
} 
A common approach in demand modeling in the literature (i.e. the supply/demand models cited above) is to choose a deterministic seasonal component plus a stochastic process modeling random deviations from the seasonal level, i.e.

$$
\text { total demand }=\text { deterministic seasonal demand }+ \text { stochastic process. }
$$

Deviations occur mainly due to weather conditions, i.e. an unusual cold spell in spring will cause a rise in demand for a few days due to electric heating. As those deviations are temporarily only the stochastic process is chosen to be mean-reverting to level zero. Any trend or seasonality is contained in the deterministic component. As an example we introduce a model for total system load with the desired properties using an Ornstein-Uhlenbeck process, which is used in Aïd et al. (2009), Coulon \& Howison (2009), and Lyle \& Elliott (2009). We measure time continuously in years and denote it by $t \in[0, T]$, where $T>0$ is some finite time horizon. All processes are defined on a probability space $(\Omega, \mathbb{P}, \mathcal{F})$ supporting Brownian motion with the filtration $\left\{\mathcal{F}_{t}\right\}=\left\{\mathcal{F}_{t}\right\}_{t \in[0, T]}$ generated by all the Brownian motions $W_{t}$ used in this paper.

Model 1.1 (Model for total system load). Denote total system load at time $t \in[0, T]$ by $L_{t}$ and assume

$$
L_{t}=\psi_{t}+l_{t}
$$

where

$\psi_{t}$ is a time-dependent deterministic load forecast, and

$l_{t}$ is an Ornstein-Uhlenbeck process, i.e.

$$
d l_{t}=-\theta^{\text {load }} l_{t} d t+\sigma^{\text {load }} d W_{t}^{\text {load }}, \quad l_{0}^{\text {load }}=l_{0} .
$$

Model 1.1 is formulated rather general. It can also be applied to log-system load ${ }^{10}$ to ensure that total system load is always positive (Coulon \& Howison 2009, Smeers \& de Maere 2010). However, as the size of the seasonal component usually overweighs the stochastic fluctuations by far, the probability of negative values is negligible. An extension with time-dependent parameters is possible (e.g. seasonal volatility as in Cartea \& Villaplana 2008).

The intra-day load pattern is very strong and possible deviations from the seasonal mean are usually present all day. Therefore in applications model 1.1 is evaluated once for each day only and the daily load curve is derived deterministically from this evaluation. This approach is taken in Smeers \& de Maere (2010) and also in section 6 of this work. Aïd et al. (2009) and Coulon \& Howison (2009) apply their models only to a single hour of the day and therefore there is no need for intra-day demand in their case studies.

Combining equ. (1) and (2) we can write the approach in this paper as follows:

$$
\begin{aligned}
\text { residual demand }= & \text { deterministic seasonal demand } \\
& + \text { stochastic process } \\
& - \text { stochastic infeed from renewables. }
\end{aligned}
$$

When applied to markets with renewables, existing demand models as expressed in equ. (2) base the calibration of demand on total demand minus infeed from renewables. Such a model does, in contrast to our approach, not distinguish between the risk from demand shocks and the uncertainty in renewable infeed.

The remainder of this paper is structured as follows. In section 2 we introduce our approach separating infeed from installed capacity. We apply this to wind and solar power infeed. The model for wind power infeed is introduced in section 3, the model for solar power infeed in section 4 . We combine both to a model for residual demand in section 5 , which we use in a case study on the German market in section 6. Concluding remarks are in section 7.

\footnotetext{
${ }^{10}$ When modeling log-load, the OU-process in equ. (3) usually has a non-zero mean-reversion level, i.e. it reads $d l_{t}=\theta^{\text {load }}\left(\mu^{\text {load }}-l_{t}\right) d t+\sigma^{\text {load }} d W_{t}^{\text {load }}$.
} 


\section{General modeling approach}

As outlined in the introduction, installed capacity of renewables has seen very strong growth in recent years, which is expected to continue in the future. This causes a trend in renewable infeed which has to be accounted for. We model the infeed from renewables independent of the installed capacity by using efficiency (also known as load factor) rather than absolute infeed. With this approach we remove the trend in infeed data caused by changes in installed capacity.

In the following, we use the placeholder src for the renewable energy source, i.e. wind or solar.

Definition 2.1 (Efficiency). We define the efficiency $E_{t}^{s r c}$ of the energy source $\operatorname{src}$ at time $t$ by

$$
E_{t}^{s r c}=\frac{A I_{t}^{s r c}}{I C_{t}^{s r c}},
$$

where

$I C_{t}^{s r c}>0$ denotes installed capacity, and

$A I_{t}^{s r c} \in\left[0, I C_{t}^{s r c}\right]$ denotes absolute infeed

of the energy source $s r c$ at time $t$. By construction we have $E_{t}^{s r c} \in[0,1]$.

In order to extend the range of possible models for $E_{t}$ we propose to map efficiency on the whole real line. There are different functions available, i.e. the inverse cdf of any distribution with support on the whole real line can be used. In our work, we use the logit-transformation, as we found that it transforms the data approximately to a normal distribution.

Definition 2.2 (Logit-transformation). The logit transformation

$$
\text { logit }:(0,1) \rightarrow \mathbb{R}
$$

of a variable $x \in(0,1)$ is defined as (Fahrmeir \& Tutz 2001)

$$
\operatorname{logit}(x)=\log \left(\frac{x}{1-x}\right)
$$

Corollary 2.3 (Inverse of logit-transformation). The logit-transformation is strictly monotonic increasing, continuously differentiable, and the inverse logit-transformation is

$$
x=\operatorname{logit}^{-1}(y)=\frac{e^{y}}{1+e^{y}}=\frac{1}{1+e^{-y}},
$$

where $y=\operatorname{logit}(x)$.

Due to the open interval of allowed values in the transformation, we must assume that we have neither zero efficiency (i.e. no infeed at all) nor full efficiency (i.e. all installed plants are fully utilized).

Assumption 2.4 (Neither zero nor full efficiency). For each energy source src and every (relevant $\left.^{11}\right)$ time $t \in[0, T]$ we assume the efficiency $E_{t}^{s r c} \in(0,1)$, i.e. we have neither zero $\left(E_{t}^{s r c}=0\right)$ nor full $\left(E_{t}^{s r c}=1\right)$ efficiency.

In later sections we find that this assumption is always fulfilled in our dataset. In the following we look at a random variable, whose logit-transformation is normally distributed.

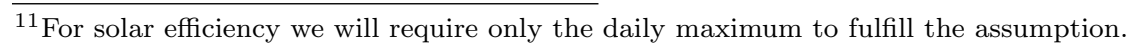




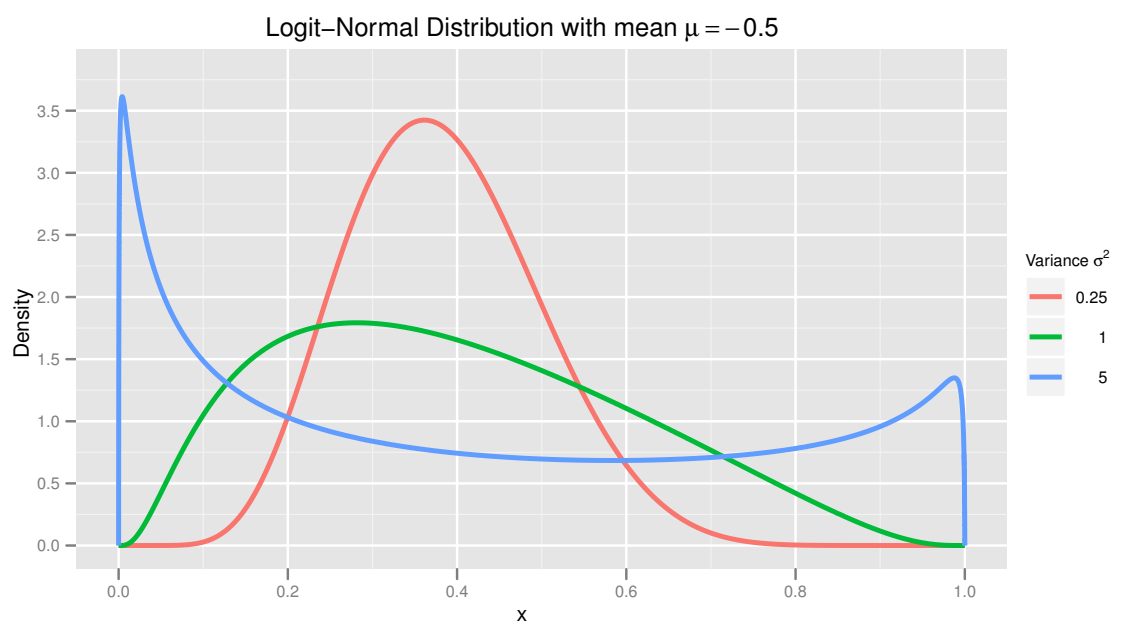

Figure 4: The logit-normal density with mean $\mu=-0.5$ and variance $\sigma^{2}=0.25,1,5$.

Definition 2.5 (Logit-normal distribution). Assume a random variable $X \in(0,1)$ and denote its logit-transformation

$$
Y:=\operatorname{logit}(X)
$$

Suppose $Y$ is normally distributed with expectation $\mu$ and standard deviation $\sigma$, i.e.

$$
Y \sim N\left(\mu, \sigma^{2}\right) .
$$

We call $X$ logitnormally distributed with mean $\mu$ and variance $\sigma^{2}$ and write $X \sim \operatorname{logit} N\left(\mu, \sigma^{2}\right)$.

The logit-normal distribution has not found much attention in the literature. It is discussed in an early work by Johnson (1949) and there is recent work of Frederic \& Lad (2008). The latter give some characteristics of the logitnormal distribution, compare it to the family of beta-distributions, and analyze the bivariate logitnormal distribution. Moreover, a generalized logitnormal-distribution using the transformation logit $\left(\frac{x}{A}\right)^{\theta}$ is analyzed in Mead (1965). Johnson (1949) shows some properties of the logitnormal distribution, in particular it is shown that the density $f_{X}$ of a logitnormally distributed random variable $X$ is unimodal if

$$
\sigma>\sqrt{2}
$$

In figure 4 we plot the logitnormal distribution for different parameter sets. Frederic \& Lad (2008) note that in the unimodal case, the logitnormal distribution looks similar to a beta-distribution on $(0,1)$. In the bimodal case, however, the beta distribution is unbounded at the boundaries, whereas the logit-normal density is not. For a discussion of the bivariate logit-normal distribution see Frederic \& Lad (2008).

We do not expect our distribution to be bimodal, as this reflects either very high infeed or rather low infeed. This is a realistic scenario in neither wind nor solar power infeed. Therefore we use equ. (5) to check calibration results.

Remark 2.6 (Parameter estimation for a logitnormally distributed random variable). Given a set of logitnormally distributed observations $A=\left\{x_{1}, x_{2}, \ldots, x_{n}\right\}$ the parameters of the logitnormal distribution are estimated in a two-step procedure:

(1) Apply the logit-transformation to the observations, i.e. calculate $\bar{A}=\left\{\operatorname{logit}\left(x_{i}\right), i=\right.$ $1,2, \ldots, n\}$. 


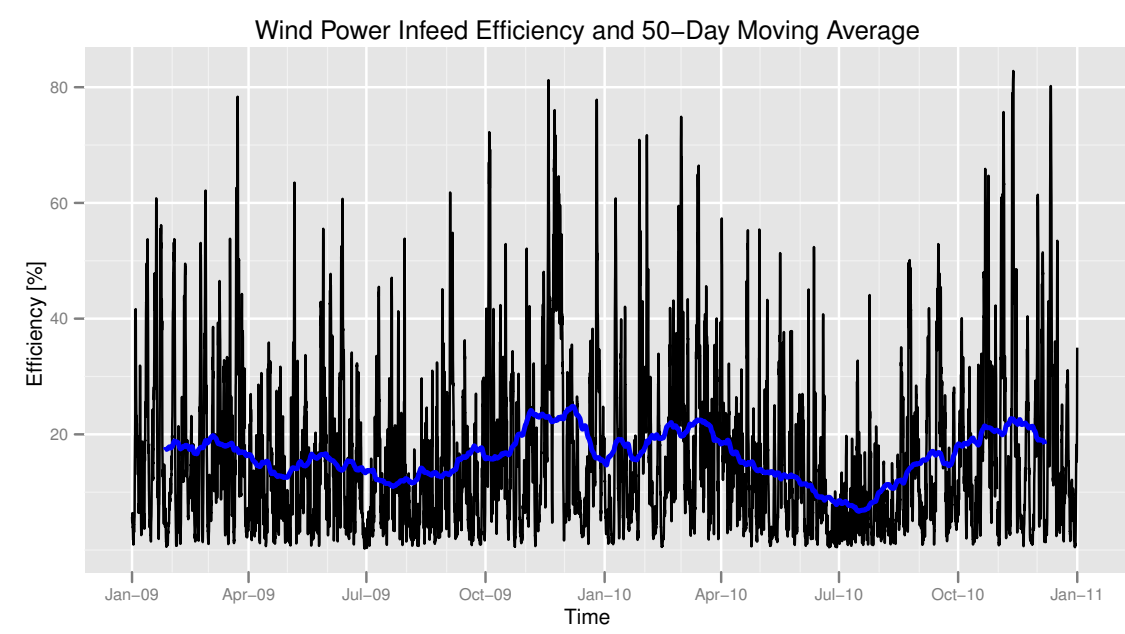

Figure 5: Hourly data of wind power infeed efficiency for Germany in 2009 and 2010, and a centered 50-day moving average.

(2) Use standard methods for the fitting of the normal distribution to $\bar{A}$ like the method of moments or maximum likelihood estimation to obtain the estimated parameters $\hat{\mu}, \hat{\sigma}^{2}$.

We use the following notation in the next sections. Under assumption 2.4 we denote the logittransformed efficiency

$$
\tilde{E}_{t}^{s r c}=\operatorname{logit}\left(E_{t}^{s r c}\right),
$$

where $\tilde{E}_{t}^{s r c} \in \mathbb{R}$. It splits into a deterministic seasonality $\eta_{t}^{s r c} \in \mathbb{R}$ and a (random) deseasonalized efficiency $\bar{E}_{t}^{s r c} \in \mathbb{R}$, i.e.

$$
\tilde{E}_{t}^{s r c}=\eta_{t}^{s c r}+\bar{E}_{t}^{s r c} \forall t \in[0, T] .
$$

We assume a yearly seasonality $\eta_{t}^{s c r}$, so it must satisfy the condition

$$
\eta_{t}^{s c r}=\eta_{t-1}^{s c r} \quad \forall t \geq 1
$$

in particular this means that $\eta_{t}^{s c r}$ contains no trend.

\section{Model for wind power infeed}

In the following we aim for a model of wind power efficiency. There already is literature on wind speed models and a good overview on the various distributions proposed is in Carta, Ramirez \& Velazquez (2009). Their results indicate that the Weibull distribution is the preferred choice in wind speed modeling. There is also literature on the generation of wind speed time series, i.e. Aksoy (2004) with an overview of the different techniques proposed.

Wind is transformed to power in an WECS (wind energy conversion system). The power generated depends on the current wind speed and the power curve of the WECS. As illustrated in Carta et al. (2009), the power curve is a non-linear function of wind speed and air density ${ }^{12}$. Therefore we cannot conclude that wind infeed also follows a Weibull distribution.

To our knowledge, the wind power infeed of a large system (like a whole country) has not yet been described in the literature. We propose a model for this in the following and motivate our

\footnotetext{
${ }^{12}$ The dependence of the power curve on air density is usually neglected in the literature and very often not even published by the manufacturer (Carta, Ramirez \& Velazquez 2008).
} 


\begin{tabular}{lrrr}
\hline Statistic & No Transformation & Logit & Deseasonalized Logit \\
\hline mean & 0.164 & -2.008 & 0.000 \\
median & 0.121 & -1.980 & 0.031 \\
standard deviation & 0.143 & 1.144 & 1.123 \\
skewness & 1.512 & -0.045 & -0.106 \\
kurtosis & 5.394 & 2.854 & 2.828 \\
minimum & 0.003 & -5.770 & -3.627 \\
maximum & 0.828 & 1.572 & 3.366 \\
\hline
\end{tabular}

Table 1: Statistical figures for the wind power efficiency data without transformation, with a logit transformation, and after deseasonalization.

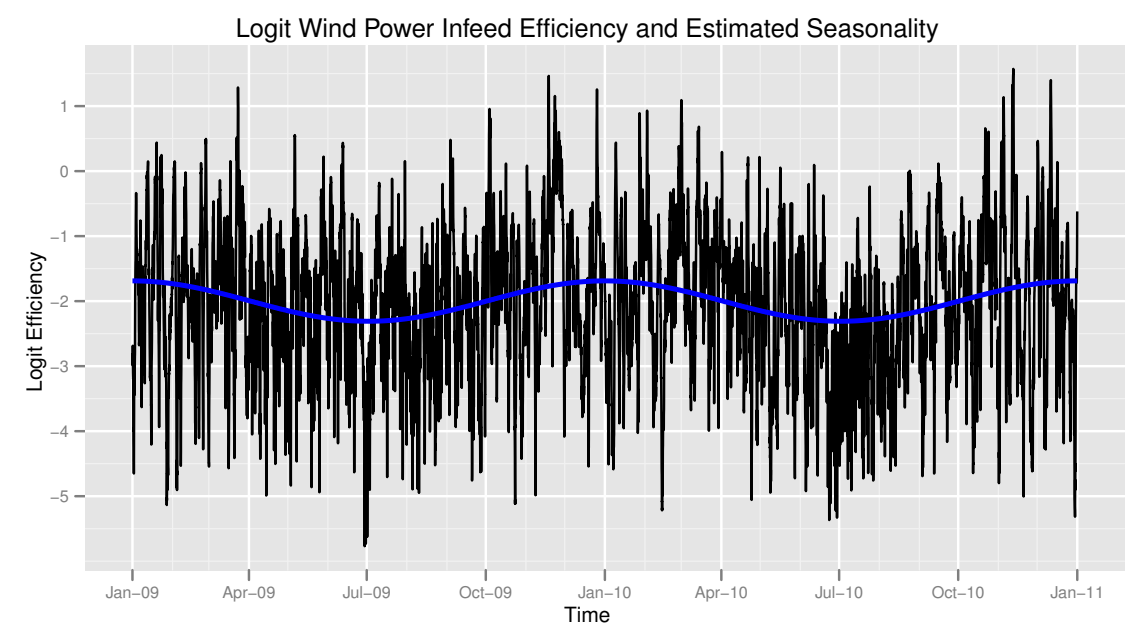

Figure 6: Logit wind power infeed efficiency for Germany in 2009 and 2010, and the seasonality estimate (blue).

choice with data on actual wind power infeed in Germany from 01/01/2009 to 31/07/2011 ${ }^{13}$. Instead of modeling wind speeds and converting it using a power curve we model wind power infeed directly.

In figure 5 we plot the data in terms of efficiency, i.e. the figure shows total infeed divided by installed capacity ${ }^{14}$. The figure includes a 50-day moving average, which motivates a seasonality with lower infeed in summer compared to the rest of the year. Moreover, the graph shows strong mean reversion and spikes, i.e. upward jumps followed by a downward jump shortly after. In table 1 we give some statistical figures of the data. In particular it can be seen that assumption 2.4 is fulfilled.

Figure 6 shows wind power infeed efficiency data after a logit-transformation. To account for seasonality we fit a function of the form

$$
\eta_{t}^{\text {wind }}=a \cos (2 \pi t+b)+c
$$

\footnotetext{
${ }^{13}$ Data for 2009 has been taken from the four TSOs' websites (http://www.tennettso.de, http://www.50hertz-transmission.net, http://www.amprion.net, and http://www.enbw.com) in October 2010. Data for 2010 and 2011 is provided by European Energy Exchange AG (2012). This data is also generated by the TSOs, but compiled into one file for each hour by the EEX.

${ }^{14}$ For 2009, we assume an installed capacity of $25.777 \mathrm{GW}$ (Bundesministerium für Umwelt Naturschutz und Reaktorsicherheit 2010), for 2010 and 2011 we have 25.961 GW and 27.547 GW, respectively (European Energy Exchange AG 2012).
} 


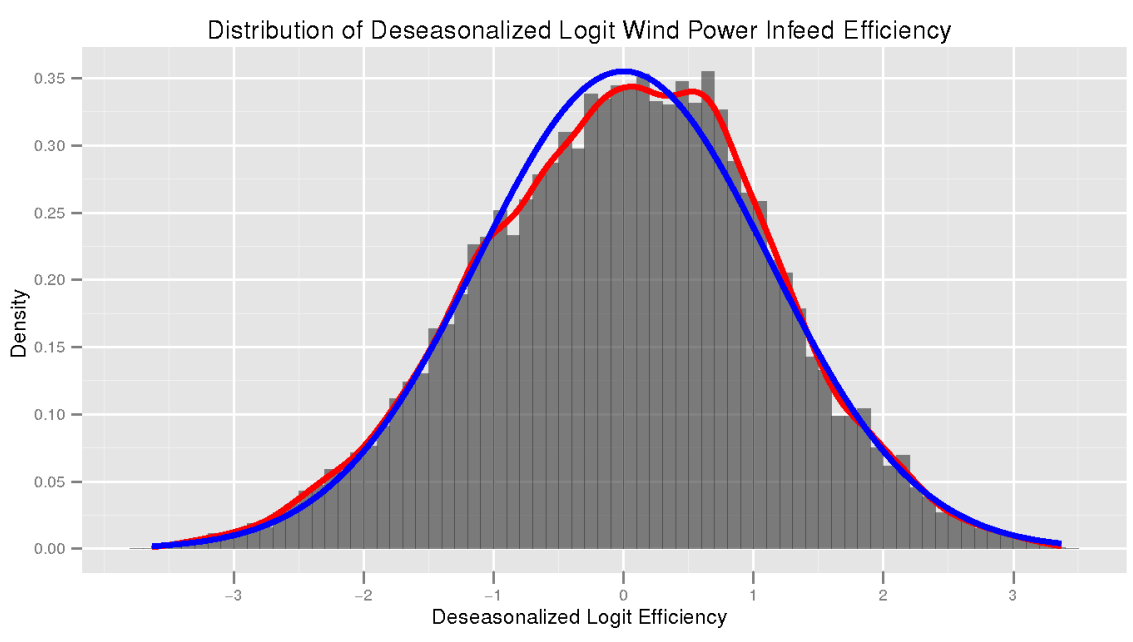

Figure 7: Histogram, empirical distribution (red line), and a fitted normal distribution (blue line) of deseasonalized logit wind power infeed efficiency.

to the data. This function fulfills the condition in equ. (7). The estimated seasonality is also plotted in figure 6 .

In the following we argue for a model describing deseasonalized efficiency $\bar{E}_{t}^{\text {wind }}$. The histogram of the deseasonalized data in figure 7 shows that the empirical distribution of the transformed data is very close to normal. This is also supported by the statistical figures in table 1, which show a skewness close to zero and a kurtosis close to three for the deseasonalized data. Mean and median are close, which supports assuming a symmetric distribution such as normal distribution. Further support for the normality assumption is given by a quantile-quantile-plot (not printed), which shows slight deviations from the normality assumptions in the tails of the data only. As we aim for a model of wind infeed over time, the results above suggest to model deseasonalized logit wind power efficiency as an Ornstein-Uhlenbeck process, which is stationary normally distributed.

Model 3.1 (Model for wind power efficiency). The model for deseasonalized logit wind power efficiency $\bar{E}_{t}^{\text {wind }}$ is

$$
d \bar{E}_{t}^{\text {wind }}=-\theta^{\text {wind }} \bar{E}_{t}^{\text {wind }} d t+\sigma^{\text {wind }} d W_{t}^{\text {wind }}, \quad \bar{E}_{0}^{\text {wind }}=e_{0},
$$

where

$$
\begin{aligned}
& e_{0} \text { is the initial value, } \\
& \theta^{\text {wind }} \text { is the mean reversion speed, and } \\
& \sigma^{\text {wind }} \text { is the volatility. }
\end{aligned}
$$

The Ornstein-Uhlenbeck process also fits an autocorrelation. The partial autocorrelation function shows clear autocorrelation in the dataset, which is 0.990 at lag one. There is also significant partial autocorrelation at lag two and three, which the Ornstein-Uhlenbeck process cannot capture. We conclude that it is important to incorporate autocorrelation in the model and that a autoregressive time-series model with higher order (e.g. three) could also be considered as an alternative. As we aim for a continuous model, we focus on model 3.1 in the following.

Proposition 3.2 (Strong solution of $\bar{E}_{t}^{\text {wind }}$ ). The SDE in equ. (9) has the strong solution

$$
\bar{E}_{t}=e_{0} e^{-\theta t}+\sigma \int_{0}^{t} e^{-\theta(t-s)} d W_{s},
$$




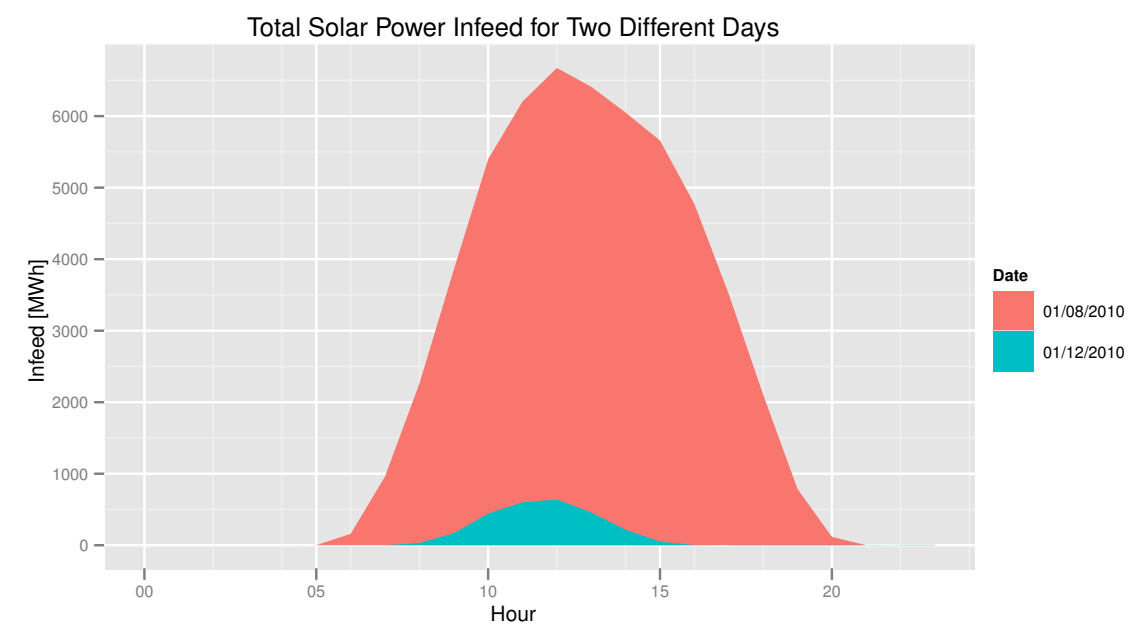

Figure 8: Solar power infeed in Germany for two days in 2010.

where we omit the superscript wind in the parameters for readability.

Its first two moments are

$$
\begin{aligned}
\mathbb{E}\left[\bar{E}_{t} \mid \bar{E}_{0}=e_{0}\right] & =e_{0} e^{-\theta t}, \\
\operatorname{Var}\left[\bar{E}_{t}\right] & =\frac{\sigma^{2}}{2 \theta}\left(1-e^{-2 \theta t}\right),
\end{aligned}
$$

and its stationary distribution is $N\left(0, \frac{\sigma^{2}}{2 \theta}\right)$.

Using the notation from definition 2.5 we say that wind infeed efficiency is modeled logitnormal.

To avoid systematic deviations from the seasonal level in future simulations (i.e. simulations not starting from an observation) we suggest to start the process in $e_{0}=0$. Moreover we assume independence of $W_{t}^{\text {load }}$ and $W_{t}^{\text {wind }}$, which is equivalent to assuming independence in the evolution of wind infeed and electricity demand. This is sensible, as there is no economic or meteorological reason to assume that wind and demand fluctuations should be correlated.

\section{Model for solar power infeed}

Production from solar power plants is gaining influence on the development of power prices in Germany due to a tremendous increase in installed capacity in recent years and the very strong daily pattern of its infeed.

The daily infeed pattern (intra-day seasonality) is illustrated in figure 8 for a summer and winter day in 2010. The shape of the infeed curve is similar and both days have a certain period of zero infeed. In more detail, we find that infeed is zero at night and, depending on the season, starts to rise at some time in the morning. It reaches its peak around noon, when solar radiation is at its highest level for the day, and decreases afterwards until there is again no infeed in the late evening and during the night. However, length and amount of infeed differs remarkably. Infeed starts earlier and lasts longer on the summer day and it has a much higher peak infeed in comparison to the winter day. Looking at time series of solar power infeed we find that the shape of the curve is resembled every day. We plot the August 2010 infeed in figure 9. 


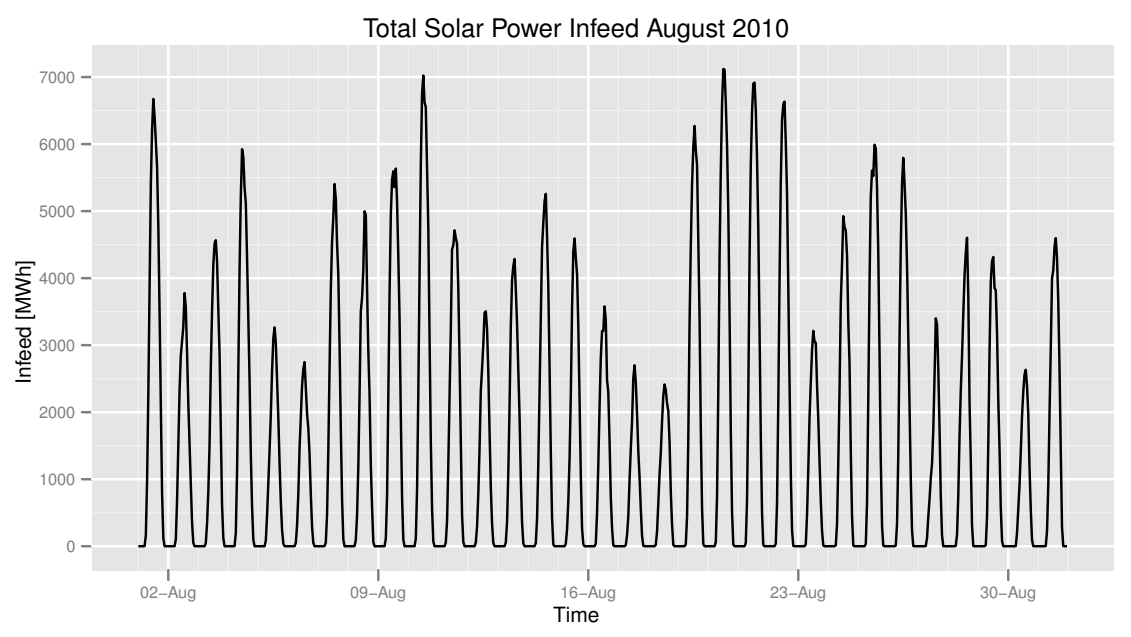

Figure 9: Solar infeed for Germany in August 2010.

This very strong pattern gives rise to a model with a deterministic daily pattern and a stochastic model with daily resolution. We propose to model the daily maximum and deduce the distribution of infeed over the day from historical data.

In the following, we formalize those ideas.

Definition 4.1 (Day-count function). The day-count function

$$
d:[0, T] \rightarrow \mathbb{N}_{0}
$$

is defined by

$$
\left(d_{t}=n\right) \equiv(t \text { is on the } \mathrm{n} \text {-th day })
$$

starting with 0 , i.e. $d_{0}=0$.

In other words, $d$ enumerates the days in $[0, T]$. For each day, we define the daily maximum process $\tilde{M}$.

Definition 4.2 (Daily maximum process). The daily maximum process of solar efficiency is defined as

$$
\tilde{M}_{i}^{\text {solar }}=\operatorname{logit}\left(\max _{\left(t: d_{t}=i\right)}\left(E_{t}^{\text {solar }}\right)\right), i=0,1, \ldots, d_{T}
$$

In figure 10 we plot the daily maximum process for our dataset. Data ranges from 01/08/2010 to $31 / 07 / 2011^{15}$. A 50 -day moving average indicates that there is clear seasonality in the data. Similar to the wind power model, we deseasonalize the daily maximum process using

$$
\eta_{t}^{\text {solar }}=a_{1} \cos \left(2 \pi t+b_{1}\right)+a_{2} \cos \left(4 \pi t+b_{2}\right)+c,
$$

which is a seasonality able to capture two peaks per year. It fulfills the condition in equ. (7). The moving average and the seasonality estimate are plotted in figure 10. The figure shows

\footnotetext{
${ }^{15}$ Actual infeed data is provided by European Energy Exchange AG (2012). For installed capacity we assume 10.644 GW and 17.320 GW for 2010 and 2011, respectively. In 2011 there was, especially in the second half of the year, a very strong rise in installed solar capacity, so we use the installed capacity which has been published by European Energy Exchange AG (2012) on 01/07/2011. The daily maximum in the data fulfills assumption 2.4. This year there was a lot of snow covering solar panels in winter (December, January), a very sunny spring (April, May) and a rainy summer (June, July). This year might be considered untypical, but due to a lack of more data we work with this dataset.
} 


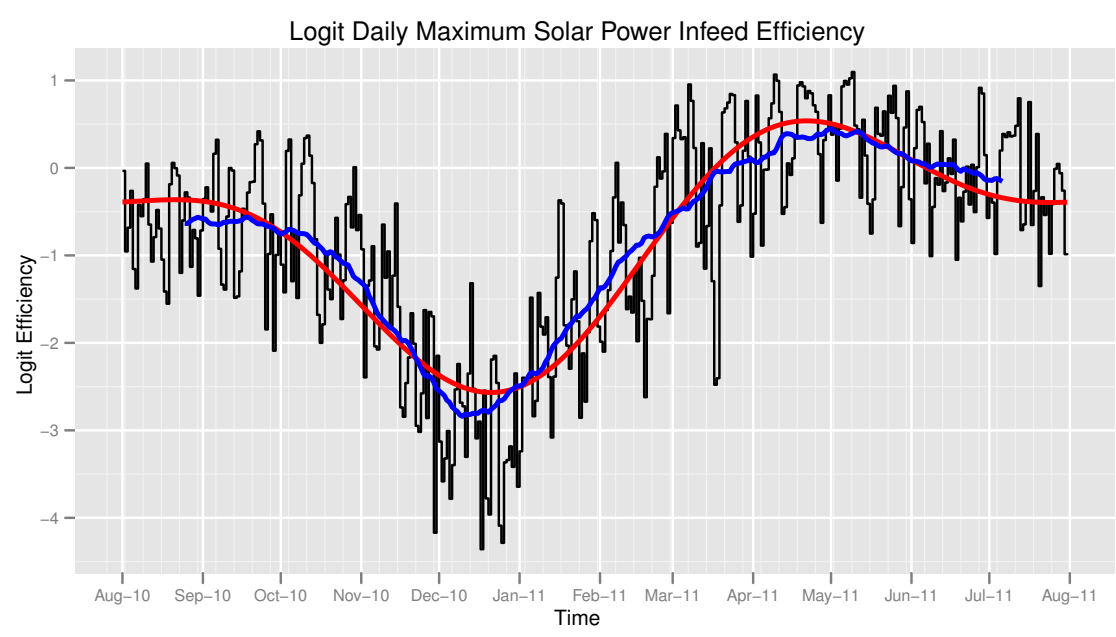

Figure 10: Solar infeed daily maximum process, 50-day moving average (blue) and estimated seasonality (red).

that the daily maximum process tends to have similar levels for a few consecutive days. This comes from weather conditions, which also tend to be similar for a few days before a change in weather implies that the process moves to another level. The process is fluctuating around zero, which motivates the choice of a mean-reverting process. Looking at the process from a time-series point of view we can analyze its partial autocorrelation function. There is strong evidence that an autoregressive model of order one is appropriate. As we have been working with continuous processes throughout this work, we choose an Ornstein-Uhlenbeck process to model the daily maximum.

Model 4.3 (Model for solar efficiency daily maximum). The model for the deseasonalized solar efficiency daily maximum $\bar{M}_{t}^{\text {solar }}$ is an Ornstein-Uhlenbeck process, i.e.

$$
d \bar{M}_{t}^{\text {solar }}=-\theta^{\text {solar }} \bar{M}_{t}^{\text {solar }} d t+\sigma^{\text {solar }} d W_{t}^{\text {solar }}, \quad \bar{M}_{0}^{\text {solar }}=m_{0},
$$

where

$$
\begin{aligned}
& m_{0} \text { is the initial value, } \\
& \theta^{\text {solar }} \text { is the mean reversion speed, and } \\
& \sigma^{\text {solar }} \text { is the volatility. }
\end{aligned}
$$

As for wind efficiency, we plot a histogram of the deseasonalized daily maximum data in figure 11. It shows that the normality assumption, which is implicit in model 4.3, is reasonable. This is also supported by the statistical figures in table 2 .

We should point at a little inconsistency in notation. In definition 4.2 we formulated the daily maximum process as a discrete process, but model 4.3 is in continuous time. This will not pose any problems on our work, as in simulations we choose the time-interval to be one day for this process. For the sake of a clean notation, one could define $\bar{M}_{i}=\max _{\left(t: d_{t}=i\right)}\left(\bar{M}_{t}^{\text {solar }}\right)$.

For the transformation from the daily maximum to the single hours over the day we use a family of deterministic functions based on historical data. This can be interpreted as the inverse transformation to the daily maximum process (see definition 4.2) and is called daily pattern transformation.

Definition 4.4 (Daily pattern transformation). The daily pattern transformation is a family of functions $\left\{\delta_{i}, i=0, \ldots, d_{T}\right\}$ with

$$
\delta_{i}:\left\{t: d_{t}=i\right\} \times(0,1) \rightarrow[0,1] .
$$




\begin{tabular}{lrrr}
\hline Statistic & No Transformation & Logit & Deseasonalized Logit \\
\hline mean & 0.358 & -0.798 & 0.000 \\
median & 0.364 & -0.396 & 0.026 \\
standard deviation & 0.209 & 0.973 & 0.703 \\
skewness & 0.069 & -0.496 & -0.262 \\
kurtosis & 1.855 & 1.980 & 3.140 \\
minimum & 0.013 & -2.567 & -2.470 \\
maximum & 0.750 & 0.538 & 1.844 \\
\hline
\end{tabular}

Table 2: Statistical figures for the solar power daily maximum efficiency data without transformation and with a logit transformation.

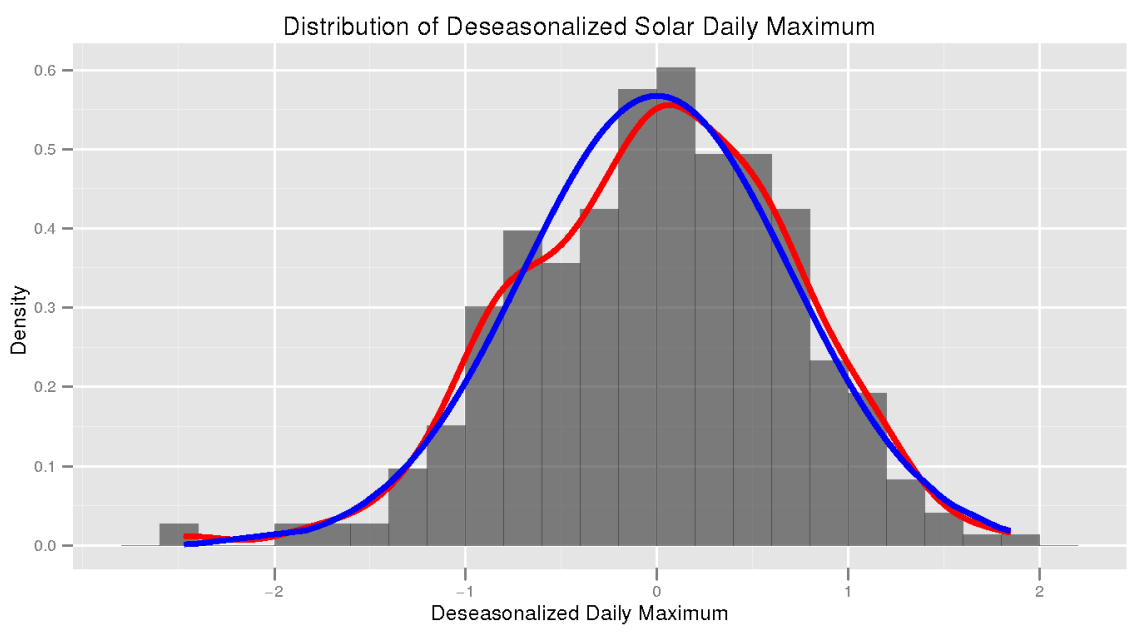

Figure 11: Histogram, empirical distribution (red line), and a fitted normal distribution (blue line) of deseasonalized daily maximum of solar power infeed efficiency.

Depending on the application, the functions $\delta_{i}$ can for example be step-functions with one step for each hour of the day or appropriately scaled Gaussian functions.

Now we have all components to formulate a model for solar power infeed at any time $t \in$ $[0, T]$.

Model 4.5 (Model for solar power efficiency). The model for solar power efficiency $E_{t}^{\text {solar }}$ at time $t \in[0, T]$ is

$$
E_{t}^{\text {solar }}=\delta_{d_{t}}\left(t, \operatorname{logit}^{-1}\left(\eta_{t}^{\text {solar }}+\bar{M}_{t}^{\text {solar }}\right)\right),
$$

where

$\bar{M}_{t}^{\text {solar }}$ is the deseasonalized daily maximum efficiency following model 4.3,

$\eta_{t}^{\text {solar }}$ is a deterministic seasonality in the daily maximum efficiency, and

$\delta_{d_{t}}$ is the daily pattern transformation for the day $d_{t}$.

A reasonable daily pattern transformation is

$$
\delta_{i}(t, x)=x \sum_{k=1}^{24} c_{k} \mathbf{1}_{t \in(\mathrm{k}-\mathrm{th} \text { hour of the day }),} c_{k} \in[0,1] \forall k,
$$

which uses a constant proportion of the daily maximum for each hour of the day. We use equ. (13) in the case study in section 6. 


\section{Residual Demand Model}

We combine the approaches for wind and solar power infeed to model residual demand.

Model 5.1 (Model for conventional demand). Suppose a model for total system load $L_{t}$, model 3.1 for wind power efficiency $E_{t}^{\text {wind }}$ and model 4.5 for solar power efficiency $E_{t}^{\text {solar }}$. Assume deterministic functions for installed capacity of wind and solar, $I C_{t}^{\text {wind }}$ and $I C_{t}^{\text {solar }}$, respectively. The conventional demand $R_{t}$, i.e. the amount of electricity to be produced by plants other than wind and solar, is modeled as

$$
R_{t}:=L_{t}-I C_{t}^{\text {wind }} \cdot E_{t}^{\text {wind }}-I C_{t}^{\text {solar }} \cdot E_{t}^{\text {solar }} .
$$

Proposition 5.2. Suppose model 5.1 with model 1.1 for total system load and assume independence of $W_{t}^{\text {load }}, W_{t}^{\text {wind }}$, and $W_{t}^{\text {solar }}$. Then the distribution of $R_{t}$ is the convolution

$$
\begin{gathered}
f_{R_{t}}(r)=\int_{0}^{1} \int_{0}^{1} \phi_{\mu^{L}, \sigma^{L}}\left(r+I C^{\text {wind }} e+I C^{\text {solar }} \delta_{d_{t}}(t, m)\right) . \\
\frac{1}{e(1-e)} \phi_{\mu^{W}, \sigma^{W}}(\operatorname{logit}(e)) \cdot \\
\frac{1}{m(1-m)} \phi_{\mu^{M}, \sigma_{t}^{M}}(\operatorname{logit}(m)) d e d m,
\end{gathered}
$$

where $\phi_{\mu, \sigma}$ is the normal density with mean $\mu$ and variance $\sigma^{2}$, and

$$
\begin{aligned}
& \mu^{L}=\psi_{t}+l_{0} e^{-\theta^{\text {load }} t} \\
& \mu^{W}=\eta_{t}^{\text {wind }}+e_{0} e^{-\theta^{\text {wind }} t} \\
& \mu^{M}=\eta_{t}+m_{0} e^{-\theta^{\text {solar }} t} \\
& \left(\sigma^{L}\right)^{2}=\frac{\left(\sigma^{\text {load }}\right)^{2}}{2 \theta^{\text {load }}}\left(1-e^{-2 \theta^{\text {load }} t}\right) \\
& \left(\sigma^{W}\right)^{2}=\frac{\left(\sigma^{\text {wind }}\right)^{2}}{2 \theta^{\text {wind }}}\left(1-e^{-2 \theta^{\text {wind }} t}\right) \\
& \left(\sigma^{M}\right)^{2}=\frac{\left(\sigma^{\text {solar }}\right)^{2}}{2 \theta^{\text {solar }}}\left(1-e^{-2 \theta^{\text {solar }} t}\right) .
\end{aligned}
$$

\section{Case Study}

In this section we apply the residual demand model to a simple supply/demand model and simulate hourly price paths of the German spot market for the year 2012 based on a calibration using data up to $31 / 07 / 2011$.

\section{Demand-Side}

We use model 1.1 for total system load prevailing at one representative hour of the day. For the yearly seasonality we use

$$
y_{t}:=a \cos (2 \pi t+b)+c
$$

which we assume is the yearly seasonality in one representative hour of the day on business days ${ }^{16}$. The representative hour must not necessarily be the hour with maximum demand, but it should preserve the weekly pattern. For the German market we propose using the time between 11am and noon. Demand on non-business days is lower due to less consumption in industry and offices (weekly seasonality). We use a constant proportion of $y_{t}$ for those days, i.e. demand at the representative hour on non-business days is

$$
(1-w) y_{t}, w \in(0,1) .
$$

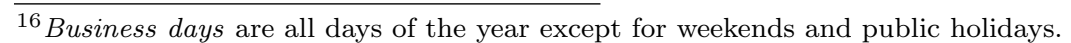




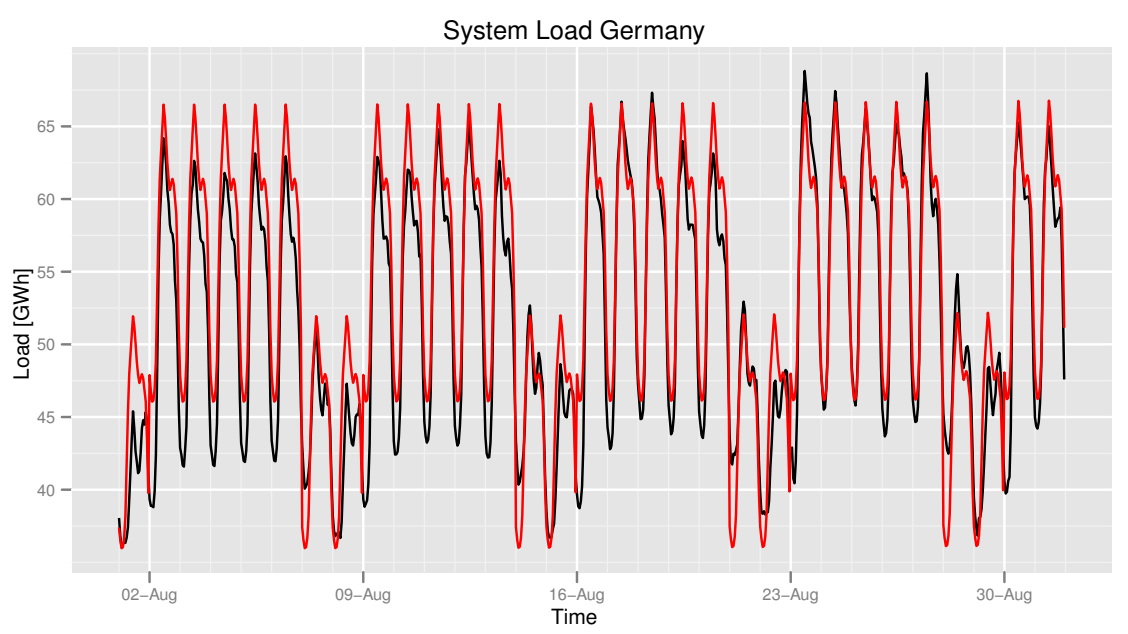

Figure 12: Actual load and seasonality estimate (red) for August 2010.

Therefore the seasonality on a daily scale is

$$
\psi_{t}=\left(1-w \mathbf{1}_{\{t \text { is weekend/public holiday }\}}\right) y_{t} .
$$

One could refine this by using different proportions for Saturdays, Sundays, and public holidays. This leaves us with the intra-day seasonality. We adopt the ideas of Smeers \& de Maere (2010) and use a time-dependent intra-day load curve $\delta_{d_{t}}^{L}$ transforming the demand of the representative hour to the single hours of the day. Using the notation from model 1.1 we model load at time $t$ as

$$
L_{t}=\delta_{d_{t}}^{L}\left(t, \psi_{t}+l_{t}\right) \text {. }
$$

\section{Calibration of the Demand Model}

We use hourly load data for Germany from 01/08/2010 through 31/07/2011 provided by ENTSOE ${ }^{17}$ for the calibration of the load seasonality and process parameters. We do not use a longer timeseries, as the economic crisis in 2009 and the beginning of 2010 lead to a downshift in electricity demand, which is not continuing in 2011. We found that the downshift influences the calibration procedure and leads to an underestimated load seasonality.

At first we calibrate the yearly seasonality $y_{t}$ using least squares on each day except for weekends and public holiday. In a second step we estimate the non-business day correction $w$ as the mean deviation on non-business days from the estimated yearly seasonality.

In a final step we specify the intra-day load curves $\delta_{t}^{L}$. Similar to the daily pattern transformation in the solar model, we use a step-function with 24 steps different for each month of the year. The function therefore takes the form

$$
\delta_{t}^{L}(x)=x \sum_{k=1}^{24} c_{k}^{L} \mathbf{1}_{t \in(\mathrm{k}-\mathrm{th} \text { hour of the day }),} c_{k}>0 \forall k .
$$

For calibration of the step weights $c_{k}^{L}$ we calculate the ratio between actual load and the reference hour (11th hour) and use the mean value as an estimate. We show in figure 12 actual load data and our seasonality estimate including the yearly, weekly and daily model.

In a final step we calibrate an Ornstein-Uhlenbeck process to the deviations between seasonality estimate and actual load at the reference hour. The estimated parameters are given in table 3 .

\footnotetext{
${ }^{17}$ https://www.entsoe.eu
} 


\begin{tabular}{rrrrr}
\hline \multicolumn{2}{c}{ Seasonality } & & \multicolumn{2}{c}{ Stochastic Process } \\
\cline { 1 - 1 } Parameter & Estimate & & Parameter & Estimate \\
\hline Load & & & \\
$a$ & 2.173 & & $\theta^{\text {load }}$ & 336.609 \\
$b$ & -0.521 & & $\sigma^{\text {load }}$ & 89.265 \\
$w$ & 68.669 & & \\
$w$ & 14.563 & & \\
\hline Wind & & & \\
$a$ & 0.311 & $\theta^{\text {wind }}$ & \\
$b$ & 0.002 & $\sigma^{\text {wind }}$ & 15.151 \\
$c$ & -1.999 & & \\
\hline Solar & & & \\
$a_{1}$ & -1.230 & $\theta^{\text {solar }}$ & 261.817 \\
$b_{1}$ & 0.476 & $\sigma^{\text {solar }}$ & 16.087 \\
$a_{2}$ & -0.614 & & \\
$b_{2}$ & 0.093 & & \\
$c$ & -0.798 & & \\
\hline
\end{tabular}

Table 3: Calibrated parameters of the residual demand model for Germany.

\section{Calibration of Wind Model}

For the calibration of the wind model we use the same data as in section 3 . As the efficiency process is stationary this does not contradict to the shorter time-series used in load and solar calibration. The estimate parameters are in table 3 . Using the calibrated parameters we find that the distribution of wind infeed efficiency is unimodal at any time $t>0$.

\section{Calibration of Solar Model}

The solar model is calibrated on the data used in section 4. The deseasonalized daily maximum process is fitted to an Ornstein-Uhlenbeck process following model 4.3. The parameters are also in table 3 and we find that the distribution of the daily maximum efficiency process is unimodal. For the daily pattern transformation (see definition 4.4) we use the functional form from equ. (13). The calibration is similar to the hourly load shape function. Separately for each month we calculate the mean of

$$
\frac{\text { actual infeed for that hour }}{\text { daily maximum infeed }}
$$

to determine $c_{k}, k=1, \ldots, 24$.

\section{Installed Capacity}

By construction of our model we need to specify values for installed capacity of wind and solar. As we aim for a simulation of the year 2012 we need to predict sensible values for $I C^{\text {wind }}$ and $I C^{\text {solar }}$. We base our estimates on scenarios for installed capacity from 50hertz et al. (2011). There are three scenarios for installed capacity, separated by technology. They distinguish onand offshore wind power, which we sum up to obtain one figure for installed wind power capacity. Scenario A is based on plans of the German government, whereas Scenario C is based on regional forecasts of the German Federal States. The basis for Scenario B is also formed by plans of the German government (i.e. Scenario A), but assumes a higher share of renewables in the system.

Using this data we obtain constant growth rates for each scenario and technology and calculate probable values for installed capacity in 2012 (see table 4). As the scenarios are based on actual data from 2010, the divergence for 2012 is not particularly big, but still there are uncertainties of 


\begin{tabular}{lrrr}
\hline Technology & Scenario A & Scenario B & Scenario C \\
\hline wind & 29.548 & 30.769 & 33.073 \\
solar & 19.000 & 20.510 & 20.027 \\
\hline
\end{tabular}

Table 4: Estimated installed capacity by technology for the year 2012 in GW based on scenarios from 50hertz et al. (2011) and assuming a constant growth rate for each technology.

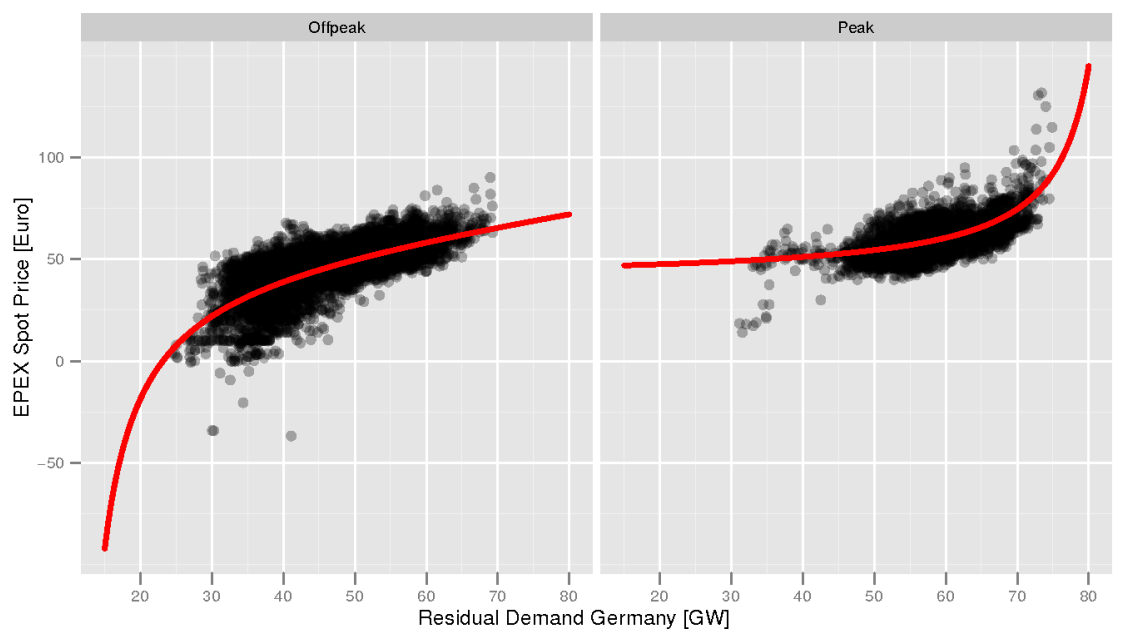

Figure 13: Residual demand against spot price and estimated supply functions (red).

up to $10 \%$. In the following analysis we will focus on Scenario A, but we will also show the effects of the different scenarios on the price development.

An alternative method to predict installed capacity is to look at power plants under construction and their expected completion date. This is especially suitable for short time horizons and wind power. Solar panels, however, are mounted mainly on private houses and have a very short time-to-build, so data on units planned or under construction can hardly be obtained.

\section{Supply-Side}

Motivated by Barlow (2002) we model the supply-side as a deterministic function $f: \mathbb{R} \rightarrow \mathbb{R}$ of residual demand, i.e.

$$
S_{t}=f\left(R_{t}\right)
$$

where $S_{t}$ denotes the spot price of power and $R_{t}$ residual demand at time $t$. The desired properties of the function $f(\cdot)$ are motivated by figure 13 , which shows historical data ${ }^{18}$ on residual demand against spot price. The figure shows a sharp increase in price at a residual demand at about $75 \mathrm{GWh}$, and on the other hand some negative prices at low residual demand. Between those extremes, the plot suggest a fairly linear relation.

We split the data in peak- and offpeak hours, as on the EEX all products are traded for base (this is all hours of the day), peak (weekdays from $8 \mathrm{am}$ to $8 \mathrm{pm}$ ), and offpeak (all but peak) hours, respectively. Therefore such a distinction does enlarge the database which can be used to calibrate the model. Moreover, it simplifies calibration of the supply function a lot. We found that the following functions provide a reasonable fit to the data with only three (two) parameters for peak (offpeak) hours.

18 Data ranges from $01 / 08 / 2010$ to $31 / 07 / 2011$. We are using this short time frame for calibration, as we have data on solar infeed for this period only. We give some statistics for the spot price in table 6 . 
Model 6.1 (Supply functions for peak and offpeak). The supply-function

$$
f: \mathbb{R} \rightarrow\left[p_{\text {floor }}, p_{\text {cap }}\right]
$$

maps residual demand to price. Define

$$
h(x, g(x))=\left\{\begin{array}{cl}
p_{\text {floor }} & x \leq x_{\text {floor }} \\
\min \left(p_{\text {cap }}, \max \left(p_{\text {floor }}, g(x)\right)\right) & x \in\left(x_{\text {floor }}, x_{\text {cap }}\right) \\
p_{\text {cap }} & x \geq x_{\text {cap }} .
\end{array}\right.
$$

For offpeak hours the supply-function is

$$
f(x)=h\left(x, g^{\text {offpeak }}(x)\right)
$$

where

For peak hours it is

$$
g^{\text {offpeak }}(x)=a+\frac{b}{x-x_{\text {floor }}}+c x
$$

$f(x)=h\left(x, g^{\text {peak }}(x)\right)$

where

$$
g^{\text {peak }}(x)=a+\frac{b}{x_{c a p}-x} .
$$

The values for price cap and floor, $p_{\text {floor }}, p_{\text {cap }}$, respectively, and load cap and floor, $x_{f l o o r}, x_{\text {cap }}$, respectively, are not calibrated to data but fixed to market-specific values.

In case of the German market, the price boundaries at the EPEX are -3000 EUR and +3000 EUR, so we choose $p_{\text {floor }}=-3000, p_{\text {cap }}=3000$. The load boundaries are less obvious, but we found $x_{\text {floor }}=10$ and $x_{c a p}=85$ to be reasonable. Note that this are boundaries on the available conventional generation power. The choice is motivated by the fact that $10 \mathrm{GW}$ of online conventional generation seems to be the minimum to ensure system stability ${ }^{19}$. The load cap at $85 \mathrm{GW}$ is justified by guaranteed capacity arguments. According to Bundesministerium für Wirtschaft und Technologie (2011) the guaranteed capacity of Germany in the year 2010 (based on a system adequacy forecast, UCTE 2009) has been 89.9 GW. Taking the nuclear moratorium ${ }^{20}$ into account we find that $85 \mathrm{GW}$ of remaining guaranteed capacity is sensible.

Using least-squares, we calibrate model 6.1 on the historical spot price data and residual demand. The resulting functions are plotted in red in figure 13. This is a calibration under the historical measure. We also calibrated the supply-functions under the risk-neutral or market measure. For this purpose we used 1000 simulations of the residual demand model under Scenario A (see before) and, using least-squares, calibrated the supply-functions on quotes of the quarterly futures from 1st of August 2011 (bold-printed data in table 7). The estimated parameters for both calibrations are in table 5.

\section{Results}

We simulate 5000 paths of residual demand for the year 2012 in order to assess the proposed model. Using the scenarios and supply functions outlined above we calculate hourly spot prices from residual demand simulations. We start with the trajectorial properties of the model. Such an analysis has already been suggested in Geman \& Roncoroni (2006) for a judgement of the quality of an electricity price model. A good trajectorial fit is also important for the valuation of path-dependent derivatives, which are found a lot in the electricity OTC-trading. Moreover, many complex riskmanagement tools require price trajectories as an input.

\footnotetext{
${ }^{19}$ For example, the installed nuclear capacity in Germany after the moratorium in 2011 is at about 12 GW, and as nuclear is usually considered a must-run plant, this also supports the choice for $x_{\text {floor }}$.

${ }^{20}$ After the moratorium 8.4 GW of installed nuclear capacity (Bundesnetzagentur 2011a) have been finally switched off, including roughly $2 \mathrm{GW}$ which were already offline for a couple of years due to technical problems. As nuclear generation is generally considered very reliable, a decrease in guaranteed capacity of 5 GW is a reasonable assumption. This is also supported by Bundesnetzagentur (2011a).
} 


\begin{tabular}{crr}
\hline Parameter & Spot Calibration & Future Calibration \\
\hline Offpeak & & \\
$a$ & 43.000 & 57.569 \\
$b$ & -713.804 & -712.733 \\
$c$ & 0.491 & 0.318 \\
\hline Peak & & \\
$a$ & 39.425 & 23.827 \\
$b$ & 528.343 & 1226.018 \\
\hline
\end{tabular}

Table 5: Parameters for peak and offpeak supply function from a calibration on EPEX day-ahead (=spot) prices from 01/08/2010 to $31 / 07 / 2011$ (spot calibration) and a calibration on EEX future prices from 01/08/2011 (future calibration).

\begin{tabular}{lr}
\hline Statistic & Value \\
\hline mean & 50.219 \\
median & 50.150 \\
standard deviation & 14.028 \\
skewness & -0.527 \\
kurtosis & 4.902 \\
minimum & -36.820 \\
maximum & 131.790 \\
\hline
\end{tabular}

Table 6: Statistics for hourly EPEX day-ahead price data from 01/08/2010 to 31/07/2011. For a plot of the data see figure 13 .

For an analysis of historical prices see section 1. In figure 14 we show sample price paths of our model. The intra-day and weekly shapes of simulated prices are displayed in figure 15, which shows the details of one trajectory over two months. The observed spot trajectory in figure 3 is less regular, but due to our simple supply side representation this model naturally cannot capture all the risks inherent in the market. However, the occurrence of both positive and negative spikes, as well as their magnitude is nicely reproduced. Moreover the model is able to reproduce the stochastic change of the daily residual load profile depending on the magnitude of renewable infeed during that day, which is visualized in figure 16. A model only based on load generates the same intraday profile for both days, whereas the residual demand model is able to produce different profiles. Therefore we believe that our model is well suited to generate trajectories with the stylized facts of observed spot prices in recent years.

Using the simulated paths we calculate forward prices. We compare our results to future price quotes from the EEX from 01/08/2011. However, we note that the simple model set up in this case study is stationary and therefore in general not well suited for the pricing of derivatives like futures or options. This is also pointed out in Barlow (2002): Since the price arises from a model for each of the supply and demand curves for power, it is easy in principle to incorporate additional factors to account for long-term effects, or changes in market structure. Such extensions of our model would be essential before it could satisfactorily deal with options and futures prices. On the other hand the calculation of forward and option prices can help us to assess the fitting quality of our model with respect to seasonal behaviour and the reproduction of extreme events. Therefore we continue with a study on forward prices, keeping in mind that the model captures only the risk inherent in load, wind, and solar fluctuations. It does in particular ignore changes in the conventional supply structure like fluctuating fuel and emission prices, power plant outages, and others.

Electricity futures have a delivery period and fulfillment can be instantaneously (which is common for exchange traded products) or at maturity. For instantaneous fulfillment we have the following 


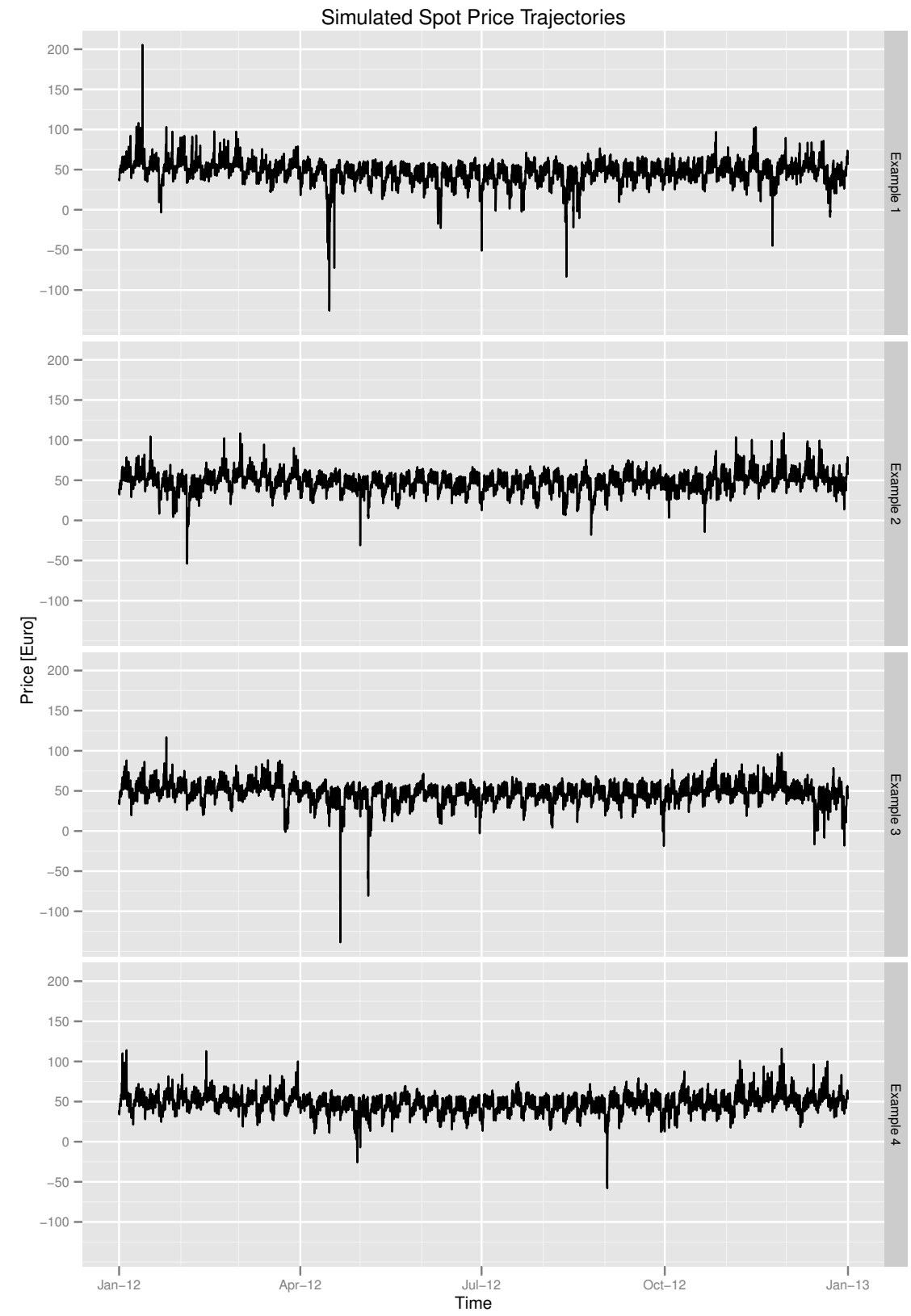

Figure 14: Sample trajectories of hourly simulated spot prices for 2012 under Scenario A. 


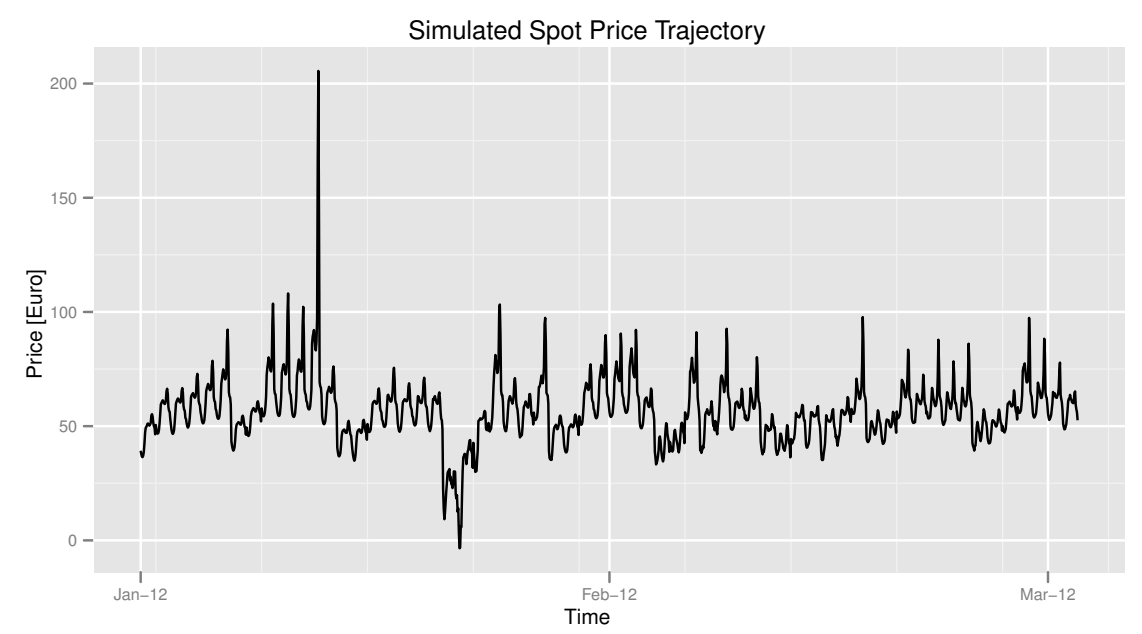

Figure 15: Detail of sample trajectory of hourly simulated spot prices for 2012 under Scenario A.
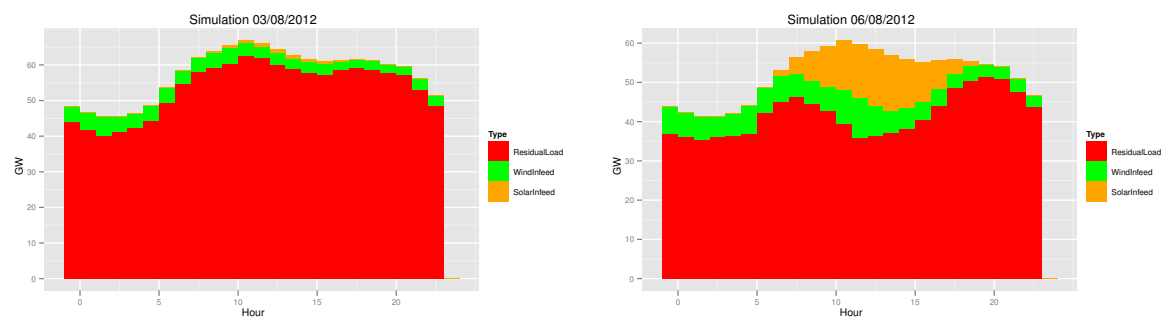

Figure 16: Simulated demand profiles for days with high and low solar infeed, respectively.

result.

Proposition 6.2 (Valuation of a forward with instantaneous fulfillment). The time-t price of a electricity forward contract with instantaneous fulfillment and delivery period $\left[T_{1}, T_{2}\right]$ is

$$
F_{t}^{\mathbb{Q}}\left(T_{1}, T_{2}\right)=\frac{r}{e^{r\left(T_{2}-T_{1}\right)}} \int_{T_{1}}^{T_{2}} e^{r\left(T_{2}-T\right)} \mathbb{E}^{\mathbb{Q}}\left[S_{T} \mid \mathcal{F}_{t}\right] d T
$$

where $\mathbb{Q}$ is the market measure (i.e. a risk-neutral measure equivalent to the real-world measure $\mathbb{P}$ and chosen by the market) and $r$ the risk-free interest rate.

Proof. The forward price (strike price) $K=F_{t}^{\mathbb{Q}}\left(T_{1}, T_{2}\right)$ is chosen such that the contract has zero expected value at time $t$ :

$$
0=\mathbb{E}^{\mathbb{Q}}\left[\int_{T_{1}}^{T_{2}} e^{r\left(T_{2}-T\right)}\left(S_{T}-K\right) d T \mid \mathcal{F}_{t}\right] .
$$

The payoff $S_{T}-K$ is received at time $T$ (instantaneous fulfillment) and reinvested (or borrowed, depending on the sign of $S_{T}-K$ ) at the risk-free rate $r$ until the final settlement at $T_{2}$. Solving equ. (16) for $K$ proves the assertion.

We assume a risk-free rate of $2 \%$ in all our calculations, i.e. $r=0.02$. In table 7 we compare forward prices under Scenario A for the spot and future calibration, i.e. we calculate $F_{t}^{\mathbb{P}}\left(T_{1}, T_{2}\right)$ 
6 Case Study

\begin{tabular}{|c|c|c|c|c|c|c|c|c|c|}
\hline \multirow{3}{*}{$\begin{array}{l}\text { Product } \\
\text { Base }\end{array}$} & \multirow{3}{*}{$\begin{array}{c}\text { Market } \\
\text { Price } \\
57.94\end{array}$} & \multicolumn{4}{|c|}{ Spot Calibration } & \multicolumn{4}{|c|}{ Future Calibration } \\
\hline & & \multirow{2}{*}{$\begin{array}{l}\text { Price } \\
49.47\end{array}$} & \multirow{2}{*}{$\begin{array}{l}\text { SD } \\
1.06\end{array}$} & \multicolumn{2}{|c|}{ Forward Premium } & \multirow{2}{*}{$\begin{array}{l}\text { Price } \\
57.95\end{array}$} & \multirow{2}{*}{$\begin{array}{c}\mathrm{SD} \\
1.22\end{array}$} & \multicolumn{2}{|c|}{ Difference } \\
\hline & & & & 8.47 & $(14.61 \%)$ & & & -0.01 & $(-0.02 \%)$ \\
\hline Peak & 71.89 & 60.21 & 0.92 & 11.68 & $(16.25 \%)$ & 71.92 & 1.67 & -0.03 & $(-0.04 \%)$ \\
\hline Offpeak & 50.21 & 43.52 & 1.40 & 6.69 & $(13.32 \%)$ & 50.21 & 1.32 & 0.00 & $(0.00 \%)$ \\
\hline Peak Q1 & 79.41 & 63.69 & 2.50 & 15.72 & $(19.80 \%)$ & 79.83 & 4.46 & -0.42 & $(-0.52 \%)$ \\
\hline Peak Q2 & 63.90 & 56.45 & 1.01 & 7.45 & $(11.65 \%)$ & 63.39 & 1.74 & 0.51 & $(0.80 \%)$ \\
\hline Peak Q3 & 64.94 & 57.42 & 0.75 & 7.52 & $(11.58 \%)$ & 65.59 & 1.73 & -0.65 & $(-1.00 \%)$ \\
\hline Peak Q4 & 79.20 & 63.22 & 2.40 & 15.98 & $(20.18 \%)$ & 78.76 & 4.32 & 0.44 & $(0.56 \%)$ \\
\hline Offpeak Q1 & 53.13 & 47.51 & 1.89 & 5.62 & $(10.58 \%)$ & 53.61 & 1.68 & -0.48 & $(-0.91 \%)$ \\
\hline Offpeak Q2 & 47.52 & 40.21 & 3.34 & 7.31 & $(15.39 \%)$ & 47.37 & 3.22 & 0.15 & $(0.33 \%)$ \\
\hline Offpeak Q3 & 47.44 & 40.68 & 3.32 & 6.76 & $(14.25 \%)$ & 47.77 & 3.20 & -0.33 & $(-0.70 \%)$ \\
\hline Offpeak Q4 & 52.76 & 45.72 & 2.23 & 7.04 & $(13.34 \%)$ & 52.10 & 2.02 & 0.66 & $(1.26 \%)$ \\
\hline Pea & 80.95 & 66.45 & 5.56 & 14.50 & $(17.91 \%)$ & 85.97 & 9.47 & -5.02 & $(-6.20 \%)$ \\
\hline Peak 02 & 81.50 & 64.04 & 4.30 & 17.46 & $(21.42 \%)$ & 80.68 & 7.56 & 0.82 & $(1.01 \%)$ \\
\hline Offpeak 01 & 54.52 & 48.17 & 2.90 & 6.35 & $(11.65 \%)$ & 54.19 & 2.55 & 0.33 & $(0.61 \%)$ \\
\hline Offpeak 02 & 54.15 & 48.03 & 3.19 & 6.12 & $(11.31 \%)$ & 54.05 & 2.80 & 0.10 & $(0.18 \%)$ \\
\hline
\end{tabular}

Table 7: Market prices for 2012 future products (01/08/2011, source www.eex.de) and simulation results under Scenario A in EUR/MWh. The absolute standard deviation (SD) and the difference to market price (absolute and as percentage) is given for all simulations. The bold printed products have been used in the future calibration. The first block are yearly products, the second quarterly and the third are monthly contracts. The remaining months were not yet traded. The difference between simulated and market prices is calculated and also given as percentage relative to market price. In case of spot calibration, this difference is known as forward premium.

and $F_{t}^{\mathbb{Q}}\left(T_{1}, T_{2}\right)$, respectively. The forward premium ${ }^{21}$ found is positive for all products ranging from $11 \%$ to $21 \%$ of market price. The premium is the highest for the products Peak Q1 and Peak Q4 (first and fourth quarter 2012) as well as Peak 01 and Peak 02 (January and February 2012). This supports the assumption that the nuclear moratorium added uncertainty in the market, especially the risk of positive spikes in times of high demand (winter months). However, liquidity in the monthly contracts was very low. The future calibration is able to significantly reduce the deviations between simulated and market prices, especially the yearly products are matched almost exactly. The difference is unusual for the Peak 01 product, which is due to the demand model not taking the Christmas holidays into account (usually the load is lower in the last and first week of the year as there is reduced industrial production). However, an even more sophisticated demandside model is not in the scope of this work, but is usually already implemented in any utility taking part in electricity trading. In general, the offpeak results are slightly better (i.e. closer to observed prices) as the peak products. This has been expected as the offpeak supply-function has three parameters, whereas for the peak supply-function only two parameters were to calibrate. However, the good fit of the remaining products and the good representation of the general shape supports our model.

The standard deviations differ remarkably between the analysed products and show seasonal behaviour. In general, a higher standard deviation is expected when demand during the delivery period is within areas of high gradient of the supply functions. Looking at the quarterly contracts, we find that for the peak products there is a lower standard deviation in the second and

\footnotetext{
${ }^{21}$ The forward premium is defined as $F_{t}^{\mathbb{Q}}\left(T_{1}, T_{2}\right)-F_{t}^{\mathbb{P}}\left(T_{1}, T_{2}\right)$, i.e. the difference between the forward price evaluated under the risk-neutral measure (which is the observed market price) and the real-world measure. There is extensive research on the forward premium in electricity markets, e.g. Bessembinder \& Lemmon (2002), Longstaff \& Wang (2004), Benth \& Meyer-Brandis (2009), and Biegler-König, Benth \& Kiesel (2011).
} 


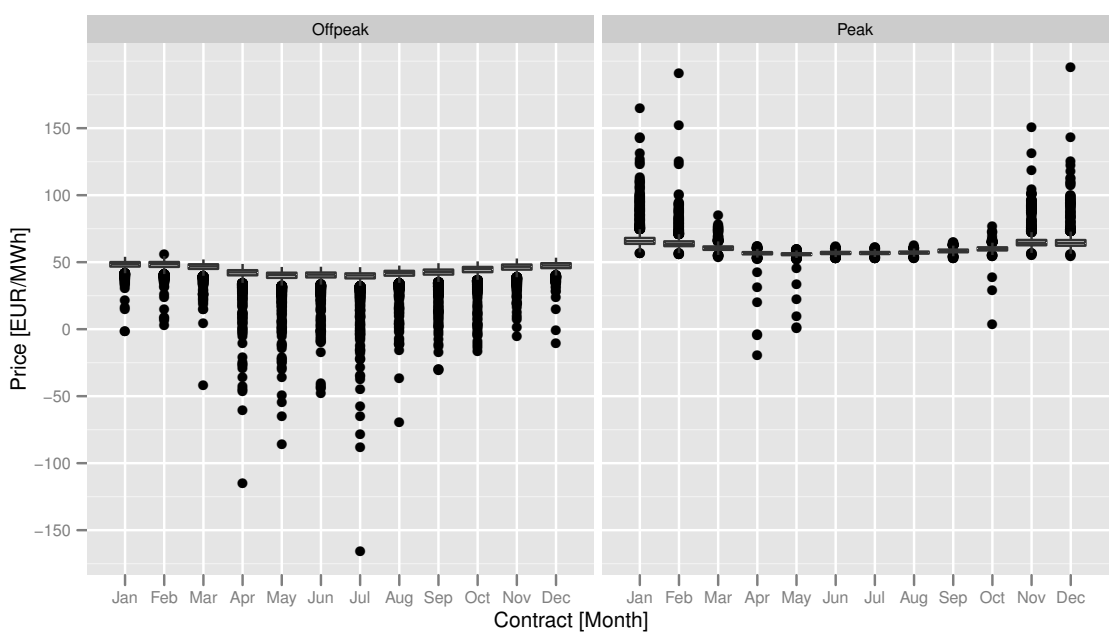

Figure 17: Boxplots of simulated prices for the monthly futures 2012 based on the spot calibration and Scenario A.

third quarter compared to others, whereas for the offpeak products the situation is vice versa. In order to assess this in more detail, we show boxplots for simulated monthly future prices 2012 in figure 17. The box, which contains $50 \%$ of the simulations, is small compared to the absolute size of the price. There are outliers for both offpeak and peak simulations. For the offpeak products, most outliers are below the box, meaning that in these paths the average price for the corresponding month is below the mean. Some outliers even have a price below zero. In those paths, the residual demand process hit the lower boundary and produced the system's minimum price of $-3000[E U R]$ for a few hours. For the peak futures, the situation is threefold. There are months with outliers mainly above the box, which correspond to the winter months with usually high demand. The April and May products show similar behavior as the offpeak futures. This is due to the solar seasonality, which has its peak in spring and there is the chance for very high solar infeed (which mainly affects the peak products). The third pattern observed is present in March, but even more pronounced in summer and early autumn. There are hardly any outliers seen in the simulations. The solar infeed for those month is fairly high, so the peak-shaving effect of solar (see also section 1) reduces the spike risk and therefore outliers above the box are rare. As the solar seasonality is lower compared to April and May, there is less chance for very high solar infeed, explaining the absence of outliers below the box.

The described effects have, to our knowledge, not yet been reported in the literature. They could have implications for the hedging strategies of both electricity consuming and electricity producing utilities. Following the results in our model, there is less risk for the consumer in an unhedged offpeak position, as the spot prices are not expected to rise far above the future price. However, there is the chance to buy electricity significantly cheaper on the spot market. On the other hand, the consumer should hedge the winter peak positions in order to reduce her spike risk. For the producer, the reverse arguments apply, i.e. she should try to sell forward her offpeak production, but for her peak production in winter she has the chance to generate much higher returns when selling on the spot. For the summer months (with hardly any outliers) the results indicate that for both, consumer and producer, there is hardly any difference to be expected between the forward sold position and the open position (which is covered on the spot). Again, however, we note that the model does not capture changes on the conventional supply structure.

Despite the stationary nature of our model we calculate the expected payoff for European call and put options on the Base 2012 future contract from the model simulations. In figure 18 


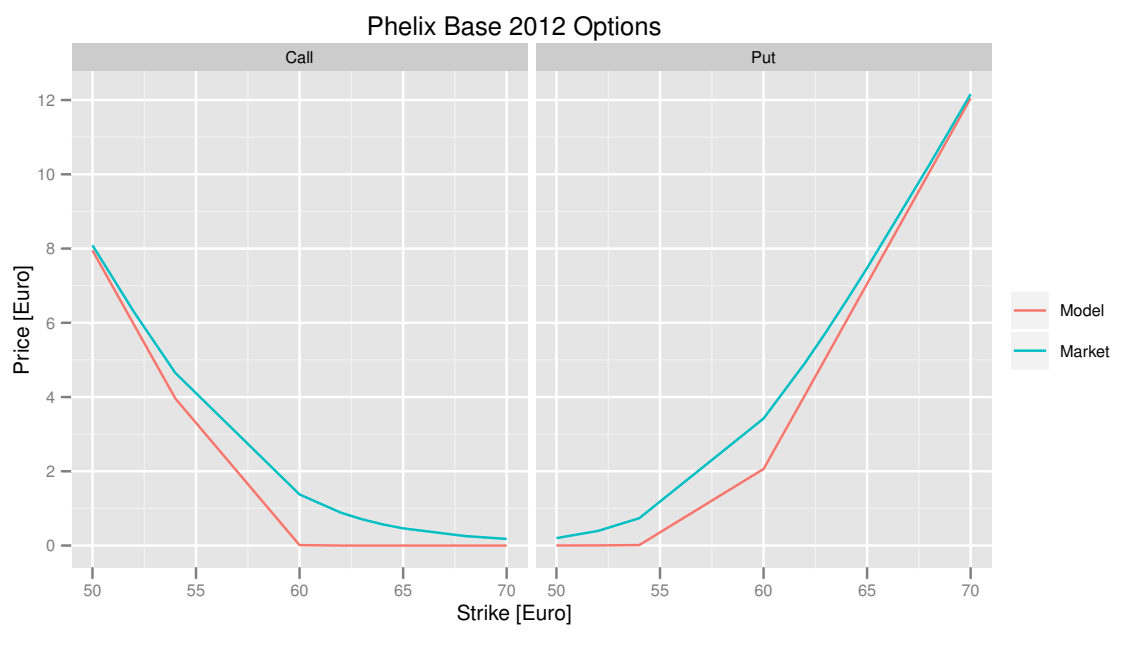

Figure 18: Expected payoff (Scenario A, future calibration) and market prices for European Call and Put Options on the Base 2012 contract with maturity January 2012.

we compare them to observed market prices. The modeled payoff is always below the observed market prices, but the model is able to capture the structure and magnitude of option prices very well. This indicates that our model performs well also on the tails of the price distribution. Naturally the model price is below the market option price due to the simplicity of the model.

The analysis conducted above was based on Scenario A only. However, as we use deterministic installed capacities in our model we can use the same paths to study prices under a different scenario. We will use the spot-calibrated supply functions in the following (otherwise a recalibration is needed as the future-calibration is obviously based on assumptions on the future installed capacities). We compare the simulated prices in table 8. We find that the prices under Scenario B are lower compared to Scenario A, and Scenario C shows even lower prices than Scenario C for all products. The decrease in price is due to the greater installed capacities for wind and solar in Scenario B and C compared to Scenario A, which, by construction, reduces wholesale electricity prices. However, the picture is less clear when looking at the volatility (standard deviation) in the market. We consider the quarterly peak and offpeak contracts. Volatility increases for all offpeak contracts, because higher renewable infeed brings residual demand more often in the steep region of the supply function. For the peak contracts, however, volatility does not change significantly, expect for the Peak Q2 product (which is the quarter with the on average highest solar infeed). We conclude that increased capacity of renewables decreases wholesale electricity market prices (known as the merit-order effect), but increases volatility in times of low demand. In order to separate the effects of wind and solar we analyse the model's sensitivity with respect to wind and solar installed capacity separately. A common procedure in sensitivity analysis is to change the parameter in question but leaving the remaining parameters unchanged. We base our analysis on the spot calibration and Scenario A and add one GW of installed capacity of wind (scenario SensWind) and solar (scenario SensSolar), respectively. The results are also displayed in table 8. Considering the Base contract we find that the overall price effect of wind is stronger than of solar. In peak hours, however, the effect is balanced. In the sunny quarters Q2 and Q3 solar has also a considerable effect on the offpeak prices. In the most expensive products (which are Peak Q1 and Peak Q4), solar shows little price decrease compared to wind. For the offpeak products, additional wind capacity generally leads to a stronger decrease in price as for additional solar capacity. Given the already high share of installed solar capacity the results indicate that new solar capacity does not have a higher merit-order effect than wind. Moreover, the sensitivity 


\begin{tabular}{|c|c|c|c|c|c|c|c|c|c|c|}
\hline \multirow[t]{2}{*}{ Product } & \multicolumn{2}{|c|}{$\begin{array}{c}\mathrm{A} \\
\text { (reference) }\end{array}$} & \multicolumn{2}{|c|}{$\begin{array}{c}\mathrm{B} \\
\text { (difference) }\end{array}$} & \multicolumn{2}{|c|}{$\begin{array}{c}\mathrm{C} \\
\text { (difference) }\end{array}$} & \multicolumn{2}{|c|}{$\begin{array}{c}\text { SensWind } \\
\text { (difference) }\end{array}$} & \multicolumn{2}{|c|}{$\begin{array}{c}\text { SensSolar } \\
\text { (difference) }\end{array}$} \\
\hline & Price & $\overline{\mathrm{SD}}$ & Price & $\overline{\mathrm{SD}}$ & Price & $\overline{\mathrm{SD}}$ & Price & $\mathrm{SD}$ & Price & $\mathrm{SD}$ \\
\hline Base & 49.47 & 1.06 & -0.51 & 0.22 & -1.19 & 0.66 & -0.27 & 0.14 & -0.11 & 0.03 \\
\hline Peak & 60.21 & 0.92 & -0.35 & 0.03 & -0.58 & 0.06 & -0.13 & 0.01 & -0.13 & 0.01 \\
\hline Offpeak & 43.52 & 1.40 & -0.59 & 0.37 & -1.53 & 1.06 & -0.35 & 0.23 & -0.10 & 0.04 \\
\hline Peak Q1 & 63.69 & 2.50 & -0.39 & -0.05 & -0.74 & -0.09 & -0.18 & -0.02 & -0.12 & -0.01 \\
\hline Peak Q2 & 56.45 & 1.01 & -0.40 & 0.42 & -0.51 & 0.82 & -0.08 & 0.17 & -0.19 & 0.09 \\
\hline Peak Q3 & 57.42 & 0.75 & -0.31 & -0.00 & -0.40 & 0.02 & -0.07 & 0.01 & -0.14 & -0.01 \\
\hline Peak Q4 & 63.22 & 2.40 & -0.31 & -0.02 & -0.67 & -0.03 & -0.18 & -0.00 & -0.07 & 0.00 \\
\hline Offpeak Q1 & 47.51 & 1.89 & -0.42 & 0.32 & -1.12 & 1.04 & -0.27 & 0.20 & -0.05 & 0.03 \\
\hline Offpeak Q2 & 40.21 & 3.34 & -0.80 & 1.02 & -1.87 & 2.72 & -0.40 & 0.58 & -0.18 & 0.15 \\
\hline Offpeak Q3 & 40.68 & 3.32 & -0.70 & 0.91 & -1.77 & 2.56 & -0.40 & 0.58 & -0.12 & 0.11 \\
\hline Offpeak Q4 & 45.72 & 2.23 & -0.44 & 0.39 & -1.34 & 1.45 & -0.33 & 0.29 & -0.02 & 0.01 \\
\hline
\end{tabular}

Table 8: Simulated future prices and empirical standard deviation (SD) under different scenarios. Scenario A is the reference scenario, for all other cases the differences with respect to the corresponding value of Scenario A are given. For Scenario A, B, and C, respectively, see table 4. Scenario SensWind and SensSolar give the results for a sensitivity analysis with respect to $1 \mathrm{GW}$ increase in installed capacity of wind and solar, respectively.

analysis supports our assumptions on price volatility. In times of low demand both wind and solar add volatility to the market, whereas volatility can be reduced in peak hours with high demand.

\section{Conclusions}

We proposed an extension to electricity demand models for markets with a considerable infeed from wind and solar power plants. It can be applied to existing supply/demand models to account for infeed from those renewables. As we model renewable infeed as demand reduction, our model is suitable for markets with a guaranteed infeed and feed-in tariff for production from renewables (like Germany). If there is no such system, production from renewables will bid at price zero (i.e. their marginal production costs) on the exchange. In this case, our approach is only suitable when additionally assuming that no negative prices are allowed at the exchange.

The model has been motivated using data from the German power market and we aggregated all wind (solar) power plants installed in Germany and are looking at it as one big plant. Therefore this model might not be suitable for modeling infeed from a single wind turbine or solar plant, as we expect much more variability on this scale. However, the wind and solar infeed models can also be used in applications other than electricity pricing, i.e. in the optimization of power plant portfolios or power plant dispatching.

The design of the model has many practical advantages. Due to the separation of total demand, wind infeed, and solar infeed a calibration of the model is easy, as data for each component is separately available. Moreover, using our model one can utilize existing supply/demand models to evaluate the impact of wind and solar infeed on electricity prices. The concept of not including installed capacity in the model (i.e. as trend) is motivated by the fact that the development of renewables can hardly be deduced from time series of historical data, as it is much more driven by exogenous factors, especially political decisions. For example, in 2012 the German government decided to cut the feed-in tariff for solar, which is expected to slow the rise of installed solar 
capacitiy. On the oher hand the German nuclear phaseout until 2022 might boost development in renewables. Effects like this or other political decisions are easy to include in our approach. When there is much uncertainty in the development of installed capacity, one could evaluate the model for different scenarios, possibly weighted by their expected probability of occurrence (those scenarios can be evaluated in a single simulation). This can also be used in risk-management or investment departments of energy utilities to assess their risk-exposure w.r.t. different development schemes.

As we made no assumption on the model for total system load (model 1.1 only served as an example), utilities can continue using their existing model for system load and extend it using our wind and solar infeed model to a more accurate residual demand model. In ongoing research, we apply the more sophisticated supply/demand model of Aïd et al. (2009) on the German market using the Residual Demand Model proposed in this paper for the demand side.

\section{References}

50hertz, Amprion, EnBW Transportnetze AG \& TenneT TSO (2011), 'Szenariorahmen für den Netzentwicklungsplan 2012'.

Aïd, R., Campi, L., Huu, A. N. \& Touzi, N. (2009), 'A structural risk-neutral model of electricity prices', International Journal of Theoretical and Applied Finance 12(07), 925-947.

Aïd, R., Campi, L. \& Langrené, N. (2012), 'A Structural Risk-Neutral Model for Pricing and Hedging Power Derivatives', Mathematical Finance (to appear).

Aksoy, H. (2004), 'Stochastic generation of hourly mean wind speed data', Renewable Energy 29(14), 2111-2131.

Barlow, M. (2002), 'A diffusion model for electricity prices', Mathematical Finance 12, 287-298.

Benth, F. E. \& Meyer-Brandis, T. (2009), 'The information premium for non-storable commodities', Journal of Energy Markets 2(3).

Bessembinder, H. \& Lemmon, M. L. (2002), 'Equilibrium Pricing and Optimal Hedging in Electricity Forward Markets', Finance 17(3).

Biegler-König, R., Benth, F. E. \& Kiesel, R. (2011), An Empirical Study on the Information Premium in Electricity Markets.

Bundesministerium für Umwelt Naturschutz und Reaktorsicherheit (2010), 'Erneuerbare Energien in Zahlen 2010'.

Bundesministerium für Umwelt Naturschutz und Reaktorsicherheit (2011), 'Erneuerbare Energien in Zahlen 2011'.

Bundesministerium für Wirtschaft und Technologie (2011), 'Monitoring-Bericht zur Versorgungssicherheit'.

Bundesnetzagentur (2011a), 'Auswirkungen des Kernkraftwerk-Moratoriums auf die Übertragungsnetze und die Versorgungssicherheit'.

Bundesnetzagentur (2011b), 'Monitoringbericht 2011'.

Burger, M., Klar, B., Müller, A. \& Schindlmayr, G. (2004), 'A spot market model for pricing derivatives in electricity markets', Quantitative Finance 4(1), 109-122.

Carmona, R., Coulon, M. \& Schwarz, D. (2011), Electricity price modeling and asset valuation: a multi-fuel structural approach.

Carta, J. A., Ramirez, P. \& Velazquez, S. (2008), 'Influence of the level of fit of a density probability function to wind-speed data on the WECS mean power output estimation', Energy Conversion and Management 49(10), 2647-2655. 
Carta, J. A., Ramirez, P. \& Velazquez, S. (2009), 'A review of wind speed probability distributions used in wind energy analysis', Renewable and Sustainable Energy Reviews 13(5), 933-955.

Cartea, A. \& Villaplana, P. (2008), 'Spot price modeling and the valuation of electricity forward contracts: The role of demand and capacity', Journal of Banking $\mathcal{G}$ Finance 32(12), 25022519.

Coulon, M. \& Howison, S. (2009), 'Stochastic Behaviour of the Electricity Bid Stack: from Fundamental Drivers to Power Prices', The Journal of Energy Markets 2(1), 29-69.

European Energy Exchange AG (2012), 'Transparency in Energy Markets'. http://www.transparency.eex.com

Fahrmeir, L. \& Tutz, G. (2001), Multivariate Statistical Modelling Based on Generalized Linear Models, Springer Series in Statistics, 2nd edn, Springer.

Frederic, P. \& Lad, F. (2008), 'Two Moments of the Logitnormal Distribution', Communications in Statistics - Simulation and Computation 37(7), 1263-1269.

Geman, H. \& Roncoroni, A. (2006), 'Understanding the Fine Structure of Electricity Prices', The Journal of Business 79(3), 1225-1261.

Johnson, N. L. (1949), 'Systems of Frequency Curves Generated by Methods of Translation', Biometrika 36(1), 149-176.

Longstaff, F. A. \& Wang, A. W. (2004), 'Electricity Forward Prices: A High-Frequency Empirical Analysis', The Journal of Finance 59(4), 1877-1900.

Lyle, M. R. \& Elliott, R. J. (2009), 'A simple hybrid model for power derivatives', Energy Economics 31(5), 757-767.

Mead, R. (1965), 'A Generalised Logit-Normal Distribution', Biometrics 21(3), 721-732.

Pirrong, C. \& Jermakyan, M. (2008), 'The price of power: The valuation of power and weather derivatives', Journal of Banking \& Finance 32(12), 2520-2529.

Renewable Energy Policy Network for the 21st Century (2011), 'Renewables 2011 - Global Status Report'.

Smeers, Y. \& de Maere, G. (2010), 'The valuation of power futures based on optimal dispatch', The Journal of Energy Markets 3(3), 27-50.

UCTE (2009), 'System Adequacy Forecast 2009 - 2020'. 


\section{Published reports of the Fraunhofer ITWM}

The PDF-files of the following reports are available under:

\section{www.itwm.fraunhofer.de/de/ zentral_berichte/berichte}

1. D. Hietel, K. Steiner, J. Struckmeier A Finite - Volume Particle Method for Compressible Flows (19 pages, 1998)

2. M. Feldmann, S. Seibold

Damage Diagnosis of Rotors: Application of Hilbert Transform and Multi-Hypothesis Testing

Keywords: Hilbert transform, damage diagnosis,

Kalman filtering, non-linear dynamics

(23 pages, 1998)

3. Y. Ben-Haim, S. Seibold

Robust Reliability of Diagnostic MultiHypothesis Algorithms: Application to Rotating Machinery

Keywords: Robust reliability, convex models, Kalman filtering, multi-hypothesis diagnosis, rotating machinery, crack diagnosis

(24 pages, 1998)

\section{F.-Th. Lentes, N. Siedow}

Three-dimensional Radiative Heat Transfer in Glass Cooling Processes

(23 pages, 1998)

5. A. Klar, R. Wegener

A hierarchy of models for multilane vehicular traffic

Part I: Modeling

(23 pages, 1998)

Part II: Numerical and stochastic investigations (17 pages, 1998)

\section{A. Klar, N. Siedow}

Boundary Layers and Domain Decomposition for Radiative Heat Transfer and Diffusion Equations: Applications to Glass Manufacturing Processes

(24 pages, 1998)

7. I. Choquet

Heterogeneous catalysis modelling and numerical simulation in rarified gas flows Part l: Coverage locally at equilibrium (24 pages, 1998)

8. J. Ohser, B. Steinbach, C. Lang Efficient Texture Analysis of Binary Images (17 pages, 1998)

9. J. Orlik

Homogenization for viscoelasticity of the integral type with aging and shrinkage (20 pages, 1998)

10. J. Mohring

Helmholtz Resonators with Large Aperture (21 pages, 1998)
11. H. W. Hamacher, A. Schöbel On Center Cycles in Grid Graphs (15 pages, 1998)

12. H. W. Hamacher, K.-H. Küfer Inverse radiation therapy planning a multiple objective optimisation approach (14 pages, 1999)

13. C. Lang, J. Ohser, R. Hilfer On the Analysis of Spatial Binary Images (20 pages, 1999)

14. M. Junk

On the Construction of Discrete Equilibrium Distributions for Kinetic Schemes (24 pages, 1999)

15. M. Junk, S. V. Raghurame Rao

A new discrete velocity method for NavierStokes equations

(20 pages, 1999)

16. H. Neunzert

Mathematics as a Key to Key Technologies (39 pages, 1999)

17. J. Ohser, K. Sandau

Considerations about the Estimation of the Size Distribution in Wicksell's Corpuscle Problem

(18 pages, 1999)

18. E. Carrizosa, H. W. Hamacher, R. Klein, S. Nickel

Solving nonconvex planar location problems by finite dominating sets

Keywords: Continuous Location, Polyhedral Gauges, Finite Dominating Sets, Approximation, Sandwich Algorithm, Greedy Algorithm

(19 pages, 2000)

\section{A. Becker}

A Review on Image Distortion Measures Keywords: Distortion measure, human visual system (26 pages, 2000)

20. H. W. Hamacher, M. Labbé, S. Nickel, T. Sonneborn

Polyhedral Properties of the Uncapacitated Multiple Allocation Hub Location Problem Keywords: integer programming, hub location, facility location, valid inequalities, facets, branch and cut (21 pages, 2000)

21. H. W. Hamacher, A. Schöbel

Design of Zone Tariff Systems in Public Transportation

(30 pages, 2001)

22. D. Hietel, M. Junk, R. Keck, D. Teleaga The Finite-Volume-Particle Method for Conservation Laws (16 pages, 2001)

23. T. Bender, H. Hennes, J. Kalcsics, M. T. Melo, S. Nickel

Location Software and Interface with GIS and Supply Chain Management Keywords: facility location, software development, geographical information systems, supply chain management

(48 pages, 2001)
24. H. W. Hamacher, S. A. Tjandra Mathematical Modelling of Evacuation Problems: A State of Art (44 pages, 2001)

25. J. Kuhnert, S. Tiwari

Grid free method for solving the Poisson equation

Keywords: Poisson equation, Least squares method, Grid free method

(19 pages, 2001)

26. T. Götz, H. Rave, D. Reinel-Bitzer, K. Steiner, $\mathrm{H}$. Tiemeier

Simulation of the fiber spinning process Keywords: Melt spinning, fiber model, Lattice Boltzmann, CFD

(19 pages, 2001)

\section{A. Zemitis}

On interaction of a liquid film with an obstacle Keywords: impinging jets, liquid film, models, numerical solution, shape

22 pages, 2001)

\section{I. Ginzburg, K. Steiner}

Free surface lattice-Boltzmann method to model the filling of expanding cavities by Bingham Fluids

Keywords: Generalized LBE, free-surface phenomena interface boundary conditions, filling processes, Bing ham viscoplastic model, regularized models

(22 pages, 2001)

\section{H. Neunzert}

"Denn nichts ist für den Menschen als Menschen etwas wert, was er nicht mit Leidenschaft tun kann

Vortrag anlässlich der Verleihung des Akademiepreises des Landes RheinlandPfalz am 21.11.2001

Keywords: Lehre, Forschung, angewandte Mathematik, Mehrskalenanalyse, Strömungsmechanik (18 pages, 2001)

30. J. Kuhnert, S. Tiwari

Finite pointset method based on the projection method for simulations of the incompressible Navier-Stokes equations

Keywords: Incompressible Navier-Stokes equations, Meshfree method, Projection method, Particle scheme, Least squares approximation

AMS subject classification: 76D05, 76M28

(25 pages, 2001)

31. R. Korn, M. Krekel

Optimal Portfolios with Fixed Consumption or Income Streams

Keywords: Portfolio optimisation, stochastic control, HJB equation, discretisation of control problems (23 pages, 2002)

32. M. Krekel

Optimal portfolios with a loan dependent credit spread

Keywords: Portfolio optimisation, stochastic control, HJB equation, credit spread, log utility, power utility, non-linear wealth dynamics

(25 pages, 2002)

33. J. Ohser, W. Nagel, K. Schladitz

The Euler number of discretized sets - on the choice of adjacency in homogeneous lattices Keywords: image analysis, Euler number, neighborhod relationships, cuboidal lattice

(32 pages, 2002) 
34. I. Ginzburg, K. Steiner

Lattice Boltzmann Model for Free-Surface flow and Its Application to Filling Process in Casting

Keywords: Lattice Boltzmann models; free-surface phenomena; interface boundary conditions; filling processes; injection molding; volume of fluid method; interface boundary conditions; advection-schemes; upwind-schemes

(54 pages, 2002)

35. M. Günther, A. Klar, T. Materne, R. Wegener

Multivalued fundamental diagrams and stop and go waves for continuum traffic equations Keywords: traffic flow, macroscopic equations, kinetic derivation, multivalued fundamental diagram, stop and go waves, phase transitions

(25 pages, 2002)

36. S. Feldmann, P. Lang, D. Prätzel-Wolters Parameter influence on the zeros of network determinants

Keywords: Networks, Equicofactor matrix polynomials, Realization theory, Matrix perturbation theory

(30 pages, 2002)

\section{K. Koch, J. Ohser, K. Schladitz} Spectral theory for random closed sets and estimating the covariance via frequency space

Keywords: Random set, Bartlett spectrum, fast Fourier transform, power spectrum

(28 pages, 2002)

\section{D. d'Humières, I. Ginzburg}

Multi-reflection boundary conditions for lattice Boltzmann models

Keywords: lattice Boltzmann equation, boudary condistions, bounce-back rule, Navier-Stokes equation

(72 pages, 2002)

\section{R. Korn}

\section{Elementare Finanzmathematik}

Keywords: Finanzmathematik, Aktien, Optionen, Portfolio-Optimierung, Börse, Lehrerweiterbildung, Mathematikunterricht

(98 pages, 2002)

40. J. Kallrath, M. C. Müller, S. Nickel

Batch Presorting Problems:

Models and Complexity Results

Keywords: Complexity theory, Integer programming,

Assigment, Logistics

(19 pages, 2002)

\section{J. Linn}

On the frame-invariant description of the phase space of the Folgar-Tucker equation Key words: fiber orientation, Folgar-Tucker equation, injection molding

(5 pages, 2003)

\section{T. Hanne, S. Nickel}

A Multi-Objective Evolutionary Algorithm for Scheduling and Inspection Planning in Software Development Projects

Key words: multiple objective programming, project management and scheduling, software development, evolutionary algorithms, efficient set

(29 pages, 2003)

43. T. Bortfeld, K.-H. Küfer, M. Monz,

A. Scherrer, C. Thieke, H. Trinkaus

Intensity-Modulated Radiotherapy - A Large Scale Multi-Criteria Programming Problem
Keywords: multiple criteria optimization, representative systems of Pareto solutions, adaptive triangulation, clustering and disaggregation techniques, visualization of Pareto solutions, medical physics, external beam radiotherapy planning, intensity modulated radiotherapy (31 pages, 2003)

\section{T. Halfmann, T. Wichmann}

Overview of Symbolic Methods in Industrial Analog Circuit Design

Keywords: $C A D$, automated analog circuit design, sym bolic analysis, computer algebra, behavioral modeling, system simulation, circuit sizing, macro modeling, differential-algebraic equations, index

(17 pages, 2003)

\section{S. E. Mikhailov, J. Orlik}

Asymptotic Homogenisation in Strength and Fatigue Durability Analysis of Composites

Keywords: multiscale structures, asymptotic homogenization, strength, fatigue, singularity, non-local conditions

(14 pages, 2003)

46. P. Domínguez-Marín, P. Hansen, N. Mladenovic, S. Nickel Heuristic Procedures for Solving the Discrete Ordered Median Problem Keywords: genetic algorithms, variable neighborhood search, discrete facility location

(31 pages, 2003)

47. N. Boland, P. Domínguez-Marín, S. Nickel, J. Puerto

Exact Procedures for Solving the Discrete Ordered Median Problem

Keywords: discrete location, Integer programming

(41 pages, 2003)

\section{S. Feldmann, P. Lang}

Padé-like reduction of stable discrete linear systems preserving their stability Keywords: Discrete linear systems, model reduction, stability, Hankel matrix, Stein equation

(16 pages, 2003)

49. J. Kallrath, S. Nicke

A Polynomial Case of the Batch Presorting Problem

Keywords: batch presorting problem, online optimization competetive analysis, polynomial algorithms, logistics (17 pages, 2003)

\section{T. Hanne, H. L. Trinkaus}

knowCube for MCDM -

Visual and Interactive Support for Multicriteria Decision Making

Key words: Multicriteria decision making, knowledge management, decision support systems, visual interfaces, interactive navigation, real-life applications. (26 pages, 2003)

51. O. lliev, V. Laptev

On Numerical Simulation of Flow Through Oil Filters

Keywords: oil filters, coupled flow in plain and porous media, Navier-Stokes, Brinkman, numerical simulation (8 pages, 2003)

52. W. Dörfler, O. Iliev, D. Stoyanov, D. Vassileva On a Multigrid Adaptive Refinement Solver for Saturated Non-Newtonian Flow in Porous Media

Keywords: Nonlinear multigrid, adaptive refinement, non-Newtonian flow in porous media

(17 pages, 2003)
53. S. Kruse

On the Pricing of Forward Starting Options under Stochastic Volatility

Keywords: Option pricing, forward starting options, Heston model, stochastic volatility, cliquet options (11 pages, 2003)

54. O. Iliev, D. Stoyanov

Multigrid - adaptive local refinement solver for incompressible flows

Keywords: Navier-Stokes equations, incompressible flow projection-type splitting, SIMPLE, multigrid methods, adaptive local refinement, lid-driven flow in a cavity (37 pages, 2003)

\section{V. Starikovicius}

The multiphase flow and heat transfer in porous media

Keywords: Two-phase flow in porous media, various formulations, global pressure, multiphase mixture model, numerical simulation

(30 pages, 2003)

\section{P. Lang, A. Sarishvili, A. Wirsen}

Blocked neural networks for knowledge extraction in the software development process Keywords: Blocked Neural Networks, Nonlinear Regression, Knowledge Extraction, Code Inspection (21 pages, 2003)

\section{H. Knaf, P. Lang, S. Zeiser}

Diagnosis aiding in Regulation

Thermography using Fuzzy Logic

Keywords: fuzzy logic, knowledge representation, expert system

(22 pages, 2003)

58. M. T. Melo, S. Nickel, F. Saldanha da Gama Largescale models for dynamic multicommodity capacitated facility location Keywords: supply chain management, strategic planning, dynamic location, modeling (40 pages, 2003)

\section{J. Orlik}

Homogenization for contact problems with periodically rough surfaces

Keywords: asymptotic homogenization, contact problems (28 pages, 2004)

60. A. Scherrer, K.-H. Küfer, M. Monz,

F. Alonso, T. Bortfeld

IMRT planning on adaptive volume structures - a significant advance of computational complexity

Keywords: Intensity-modulated radiation therapy (IMRT), inverse treatment planning, adaptive volume structures, hierarchical clustering, local refinement, adaptive clustering, convex programming, mesh generation, multi-grid methods

(24 pages, 2004)

61. D. Kehrwald

Parallel lattice Boltzmann simulation of complex flows

Keywords: Lattice Boltzmann methods, parallel computing, microstructure simulation, virtual material design, pseudo-plastic fluids, liquid composite moulding (12 pages, 2004)

62. O. Iliev, J. Linn, M. Moog, D. Niedziela, V. Starikovicius

On the Performance of Certain Iterative Solvers for Coupled Systems Arising in Discretization of Non-Newtonian Flow Equations 
Keywords: Performance of iterative solvers, Preconditioners, Non-Newtonian flow

(17 pages, 2004)

\section{R. Ciegis, O. Iliev, S. Rief, K. Steiner}

On Modelling and Simulation of Different Regimes for Liquid Polymer Moulding Keywords: Liquid Polymer Moulding, Modelling, Simulation, Infiltration, Front Propagation, non-Newtonian flow in porous media

(43 pages, 2004)

\section{T. Hanne, H. Neu}

Simulating Human Resources in

\section{Software Development Processes}

Keywords: Human resource modeling, software process, productivity, human factors, learning curve

(14 pages, 2004)

\section{O. Iliev, A. Mikelic, P. Popov}

Fluid structure interaction problems in de-

formable porous media: Toward permeability of deformable porous media

Keywords: fluid-structure interaction, deformable porous media, upscaling, linear elasticity, stokes, finite elements

(28 pages, 2004)

66. F. Gaspar, O. Iliev, F. Lisbona, A. Naumovich, P. Vabishchevich

On numerical solution of 1-D poroelasticity equations in a multilayered domain Keywords: poroelasticity, multilayered material, finite volume discretization, MAC type grid

(41 pages, 2004)

67. J. Ohser, K. Schladitz, K. Koch, M. Nöthe Diffraction by image processing and its application in materials science

Keywords: porous microstructure, image analysis, random set, fast Fourier transform, power spectrum, Bartlett spectrum

(13 pages, 2004)

\section{H. Neunzert}

\section{Mathematics as a Technology: Challenges} for the next 10 Years

Keywords: applied mathematics, technology, modelling, simulation, visualization, optimization, glass processing, spinning processes, fiber-fluid interaction, trubulence effects, topological optimization, multicriteria optimization, Uncertainty and Risk, financial mathematics, Malliavin calculus, Monte-Carlo methods, virtual material design, filtration, bio-informatics, system biology

(29 pages, 2004)

69. R. Ewing, O. lliev, R. Lazarov, A. Naumovich On convergence of certain finite difference discretizations for $1 D$ poroelasticity interface problems

Keywords: poroelasticity, multilayered material, finite volume discretizations, MAC type grid, error estimates (26 pages, 2004 )

70. W. Dörfler, O. Iliev, D. Stoyanov, D. Vassileva On Efficient Simulation of Non-Newtonian Flow in Saturated Porous Media with a Multigrid Adaptive Refinement Solver Keywords: Nonlinear multigrid, adaptive renement non-Newtonian in porous media (25 pages, 2004)

\section{J. Kalcsics, S. Nickel, M. Schröde}

Towards a Unified Territory Design Approach - Applications, Algorithms and GIS Integration Keywords: territory desgin, political districting, sales territory alignment, optimization algorithms, Geographical Information Systems

(40 pages, 2005)
72. K. Schladitz, S Peters, D Reinel-Bitzer, A. Wiegmann, J. Ohser

Design of acoustic trim based on geometric modeling and flow simulation for non-woven Keywords: random system of fibers, Poisson line process, flow resistivity, acoustic absorption, Lattice-Boltzmann method, non-woven (21 pages, 2005)

\section{V. Rutka, A. Wiegmann}

Explicit Jump Immersed Interface Method for virtual material design of the effective elastic moduli of composite materials Keywords: virtual material design, explicit jump immersed interface method, effective elastic moduli, composite materials

(22 pages, 2005)

\section{T. Hanne}

Eine Übersicht zum Scheduling von Baustellen Keywords: Projektplanung, Scheduling, Bauplanung, Bauindustrie

(32 pages, 2005)

75. J. Linn

The Folgar-Tucker Model as a Differetial Algebraic System for Fiber Orientation Calculation

Keywords: fiber orientation, Folgar-Tucker model, invariants, algebraic constraints, phase space, trace stability

(15 pages, 2005)

76. M. Speckert, K. Dreßler, H. Mauch, A. Lion, G. J. Wierda

Simulation eines neuartigen Prüfsystems für Achserprobungen durch MKS-Modellierung einschließlich Regelung Keywords: virtual test rig, suspension testing, multibody simulation, modeling hexapod test rig, opti mization of test rig configuration

(20 pages, 2005)

77. K.-H. Küfer, M. Monz, A. Scherrer, P. Süss, F. Alonso, A. S. A. Sultan, Th. Bortfeld,

D. Craft, Chr. Thieke

Multicriteria optimization in intensity modulated radiotherapy planning Keywords: multicriteria optimization, extreme solutions, real-time decision making, adaptive approxima tion schemes, clustering methods, IMRT planning, reverse engineering

(51 pages, 2005)

78. S. Amstutz, H. Andrä

A new algorithm for topology optimization using a level-set method

Keywords: shape optimization, topology optimization, topological sensitivity, level-set

(22 pages, 2005)

\section{N. Ettrich}

Generation of surface elevation models for urban drainage simulation

Keywords: Flooding, simulation, urban elevation models, laser scanning

(22 pages, 2005

80. H. Andrä, J. Linn, I. Matei, I. Shklyar, K. Steiner, E. Teichmann

OPTCAST - Entwicklung adäquater Struk turoptimierungsverfahren für Gießereien Technischer Bericht (KURZFASSUNG) Keywords: Topologieoptimierung, Level-Set-Methode Gießprozesssimulation, Gießtechnische Restriktionen, CAE-Kette zur Strukturoptimierung

(77 pages, 2005)
81. N. Marheineke, R. Wegener Fiber Dynamics in Turbulent Flows Part I: General Modeling Framework Keywords: fiber-fluid interaction; Cosserat rod; turbuence modeling: Kolmogorov's energy spectrum; double-velocity correlations; differentiable Gaussian fields (20 pages, 2005)

\section{Part II: Specific Taylor Drag}

Keywords: flexible fibers; $k-\varepsilon$ turbulence model; fiber-turbulence interaction scales; air drag; random Gaussian aerodynamic force; white noise; stochastic differential equations; ARMA process

(18 pages, 2005)

\section{C. H. Lampert, O. Wirjadi}

An Optimal Non-Orthogonal Separation of the Anisotropic Gaussian Convolution Filter Keywords: Anisotropic Gaussian filter, linear filtering, or entation space, $n D$ image processing, separable filters (25 pages, 2005)

83. H. Andrä, D. Stoyanov

Error indicators in the parallel finite element solver for linear elasticity DDFEM Keywords: linear elasticity, finite element method, hierarchical shape functions, domain decom-position, parallel implementation, a posteriori error estimates (21 pages, 2006)

84. M. Schröder, I. Solchenbach Optimization of Transfer Quality in Regional Public Transit

Keywords: public transit, transfer quality, quadratic assignment problem

(16 pages, 2006

85. A. Naumovich, F. J. Gaspar

On a multigrid solver for the three-dimensional Biot poroelasticity system in multilayered domains

Keywords: poroelasticity, interface problem, multigrid, operator-dependent prolongation

(11 pages, 2006)

86. S. Panda, R. Wegener, N. Marheineke Slender Body Theory for the Dynamics of Curved Viscous Fibers

Keywords: curved viscous fibers; fluid dynamics; NavierStokes equations; free boundary value problem; asymp totic expansions; slender body theory

(14 pages, 2006)

87. E. Ivanov, H. Andrä, A. Kudryavtsev Domain Decomposition Approach for Automatic Parallel Generation of Tetrahedral Grids Key words: Grid Generation, Unstructured Grid, Delau nay Triangulation, Parallel Programming, Domain Decomposition, Load Balancing

(18 pages, 2006)

88. S. Tiwari, S. Antonov, D. Hietel, J. Kuhnert, R. Wegener

A Meshfree Method for Simulations of In teractions between Fluids and Flexible Structures

Key words: Meshfree Method, FPM, Fluid Structure Interaction, Sheet of Paper, Dynamical Coupling (16 pages, 2006)

89. R. Ciegis, O. Iliev, V. Starikovicius, K. Steine Numerical Algorithms for Solving Problems of Multiphase Flows in Porous Media Keywords: nonlinear algorithms, finite-volume method software tools, porous media, flows

16 pages, 2006) 
90. D. Niedziela, O. Iliev, A. Latz

On 3D Numerical Simulations of Viscoelastic Fluids

Keywords: non-Newtonian fluids, anisotropic viscosity, integral constitutive equation

(18 pages, 2006)

\section{A. Winterfeld}

Application of general semi-infinite Programming to Lapidary Cutting Problems Keywords: large scale optimization, nonlinear programming, general semi-infinite optimization, design centering, clustering

(26 pages, 2006)

\section{J. Orlik, A. Ostrovska}

Space-Time Finite Element Approximation and Numerical Solution of Hereditary Linear Viscoelasticity Problems

Keywords: hereditary viscoelasticity; kern approximation by interpolation; space-time finite element approximation, stability and a priori estimate

(24 pages, 2006)

93. V. Rutka, A. Wiegmann, H. Andrä EJIIM for Calculation of effective Elastic Moduli in 3D Linear Elasticity

Keywords: Elliptic $P D E$, linear elasticity, irregular domain, finite differences, fast solvers, effective elastic moduli

(24 pages, 2006)

\section{A. Wiegmann, A. Zemitis}

EJ-HEAT: A Fast Explicit Jump Harmonic Averaging Solver for the Effective Heat Conductivity of Composite Materials Keywords: Stationary heat equation, effective thermal conductivity, explicit jump, discontinuous coefficients, virtual material design, microstructure simulation, EJ-HEAT

(21 pages, 2006)

\section{A. Naumovich}

On a finite volume discretization of the three-dimensional Biot poroelasticity system in multilayered domains

Keywords: Biot poroelasticity system, interface problems, finite volume discretization, finite difference method (21 pages, 2006)

\section{M. Krekel, J. Wenzel}

A unified approach to Credit Default Swaption and Constant Maturity Credit Default Swap valuation

Keywords: LIBOR market model, credit risk, Credit Default Swaption, Constant Maturity Credit Default Swapmethod

(43 pages, 2006)

\section{A. Dreyer}

\section{Interval Methods for Analog Circiuts}

Keywords: interval arithmetic, analog circuits, tolerance analysis, parametric linear systems, frequency response, symbolic analysis, CAD, computer algebra

(36 pages, 2006)

98. N. Weigel, S. Weihe, G. Bitsch, K. Dreßler Usage of Simulation for Design and Optimization of Testing

Keywords: Vehicle test rigs, MBS, control, hydraulics,

testing philosophy

(14 pages, 2006)

99. H. Lang, G. Bitsch, K. Dreßler, M. Speckert Comparison of the solutions of the elastic and elastoplastic boundary value problems
Keywords: Elastic BVP, elastoplastic BVP, variational inequalities, rate-independency, hysteresis, linear kinematic hardening, stop- and play-operator

(21 pages, 2006)

100. M. Speckert, K. Dreßler, H. Mauch MBS Simulation of a hexapod based suspension test rig

Keywords: Test rig, MBS simulation, suspension,

hydraulics, controlling, design optimization

(12 pages, 2006)

101. S. Azizi Sultan, K.-H. Küfer

A dynamic algorithm for beam orientations in multicriteria IMRT planning

Keywords: radiotherapy planning, beam orientation optimization, dynamic approach, evolutionary algorithm, global optimization

(14 pages, 2006)

102. T. Götz, A. Klar, N. Marheineke, R. Wegener A Stochastic Model for the Fiber Lay-down Process in the Nonwoven Production Keywords: fiber dynamics, stochastic Hamiltonian system, stochastic averaging

(17 pages, 2006)

103. Ph. Süss, K.-H. Küfer

Balancing control and simplicity: a variable aggregation method in intensity modulated radiation therapy planning

Keywords: IMRT planning, variable aggregation, clustering methods

(22 pages, 2006)

104. A. Beaudry, G. Laporte, T. Melo, S. Nickel Dynamic transportation of patients in hospitals

Keywords: in-house hospital transportation, dial-a-ride, dynamic mode, tabu search

(37 pages, 2006)

105. Th. Hanne

Applying multiobjective evolutionary algorithms in industrial projects

Keywords: multiobjective evolutionary algorithms, discrete optimization, continuous optimization, electronic circuit design, semi-infinite programming, scheduling (18 pages, 2006)

106. J. Franke, S. Halim

Wild bootstrap tests for comparing signals and images

Keywords: wild bootstrap test, texture classification, textile quality control, defect detection, kernel estimate, nonparametric regression

(13 pages, 2007)

107. Z. Drezner, S. Nickel

Solving the ordered one-median problem in the plane

Keywords: planar location, global optimization, ordered median, big triangle small triangle method, bounds, numerical experiments

(21 pages, 2007)

108. Th. Götz, A. Klar, A. Unterreiter, R. Wegener

Numerical evidance for the non-existing of solutions of the equations desribing rotational fiber spinning

Keywords: rotational fiber spinning, viscous fibers, boundary value problem, existence of solutions (11 pages, 2007)
109. Ph. Süss, K.-H. Küfer

Smooth intensity maps and the BortfeldBoyer sequencer

Keywords: probabilistic analysis, intensity modulated radiotherapy treatment (IMRT), IMRT plan application step-and-shoot sequencing

(8 pages, 2007)

110. E. Ivanov, O. Gluchshenko, H. Andrä, A. Kudryavtsev

Parallel software tool for decomposing and meshing of $3 d$ structures

Keywords: a-priori domain decomposition, unstructured grid, Delaunay mesh generation

(14 pages, 2007)

111. O. Iliev, R. Lazarov, J. Willems Numerical study of two-grid preconditioners for 1d elliptic problems with highly oscillating discontinuous coefficients Keywords: two-grid algorithm, oscillating coefficients, preconditioner

(20 pages, 2007)

112. L. Bonilla, T. Götz, A. Klar, N. Marheineke, R. Wegener

Hydrodynamic limit of the Fokker-Planckequation describing fiber lay-down processes

Keywords: stochastic dierential equations, FokkerPlanck equation, asymptotic expansion, Ornstein-

Uhlenbeck process

(17 pages, 2007)

\section{S. Rief}

Modeling and simulation of the pressing section of a paper machine

Keywords: paper machine, computational fluid dynamics, porous media

(41 pages, 2007)

114. R. Ciegis, O. Iliev, Z. Lakdawala

On parallel numerical algorithms for simulating industrial filtration problems

Keywords: Navier-Stokes-Brinkmann equations, finite volume discretization method, SIMPLE, parallel computing, data decomposition method

(24 pages, 2007)

\section{N. Marheineke, R. Wegener}

Dynamics of curved viscous fibers with surface tension

Keywords: Slender body theory, curved viscous bers with surface tension, free boundary value problem (25 pages, 2007)

116. S. Feth, J. Franke, M. Speckert Resampling-Methoden zur mse-Korrektur und Anwendungen in der Betriebsfestigkeit Keywords: Weibull, Bootstrap, Maximum-Likelihood, Betriebsfestigkeit

(16 pages, 2007)

117. H. Knaf

Kernel Fisher discriminant functions - a concise and rigorous introduction

Keywords: wild bootstrap test, texture classification, textile quality control, defect detection, kernel estimate, nonparametric regression

(30 pages, 2007)

118. O. Iliev, I. Rybak

On numerical upscaling for flows in heterogeneous porous media 
Keywords: numerical upscaling heterogeneous porous media, single phase flow, Darcy's law, multiscale problem, effective permeability, multipoint flux approximation, anisotropy

(17 pages, 2007)

\section{O. Iliev, I. Rybak}

On approximation property of multipoint flux approximation method

Keywords: Multipoint flux approximation, finite volume method, elliptic equation, discontinuous tensor coeffi-

cients, anisotropy

(15 pages, 2007)

120. O. Iliev, I. Rybak, J. Willems

On upscaling heat conductivity for a class of industrial problems

Keywords: Multiscale problems, effective heat conductivity, numerical upscaling, domain decomposition

(21 pages, 2007)

121. R. Ewing, O. Iliev, R. Lazarov, I. Rybak On two-level preconditioners for flow in porous media

Keywords: Multiscale problem, Darcy's law, single phase flow, anisotropic heterogeneous porous media, numerical upscaling, multigrid, domain decomposition, efficient preconditioner

(18 pages, 2007)

122. M. Brickenstein, A. Dreyer

POLYBORI: A Gröbner basis framework for Boolean polynomials

Keywords: Gröbner basis, formal verification, Boolean polynomials, algebraic cryptoanalysis, satisfiability

(23 pages, 2007)

\section{O. Wirjad}

Survey of $3 d$ image segmentation methods Keywords: image processing, 3d, image segmentation, binarization

(20 pages, 2007)

\section{S. Zeytun, A. Gupta}

A Comparative Study of the Vasicek and the CIR Model of the Short Rate

Keywords: interest rates, Vasicek model, CIR-model,

calibration, parameter estimation

(17 pages, 2007)

\section{G. Hanselmann, A. Sarishvili}

Heterogeneous redundancy in software quality prediction using a hybrid Bayesian approach

Keywords: reliability prediction, fault prediction, nonhomogeneous poisson process, Bayesian model averaging

(17 pages, 2007)

126. V. Maag, M. Berger, A. Winterfeld, K.-H Küfer

A novel non-linear approach to minimal area rectangular packing

Keywords: rectangular packing, non-overlapping constraints, non-linear optimization, regularization, relaxation

(18 pages, 2007)

127. M. Monz, K.-H. Küfer, T. Bortfeld, C. Thieke Pareto navigation - systematic multi-criteria-based IMRT treatment plan determination

Keywords: convex, interactive multi-objective optimization, intensity modulated radiotherapy planning

(15 pages, 2007)
128. M. Krause A Scherrer

On the role of modeling parameters in IMRT plan optimization

Keywords: intensity-modulated radiotherapy (IMRT) inverse IMRT planning, convex optimization, sensitivity analysis, elasticity, modeling parameters, equivalent uniform dose (EUD)

(18 pages, 2007)

\section{A. Wiegmann}

Computation of the permeability of porous materials from their microstructure by FFFStokes

Keywords: permeability, numerical homogenization

fast Stokes solver

(24 pages, 2007)

130. T. Melo, S. Nickel, F. Saldanha da Gama Facility Location and Supply Chain Management - A comprehensive review

Keywords: facility location, supply chain management, network design

(54 pages, 2007)

131. T. Hanne, T. Melo, S. Nickel

Bringing robustness to patient flow management through optimized patient transports in hospitals

Keywords: Dial-a-Ride problem, online problem, case study tabu search, hospital logistics

(23 pages, 2007)

132. R. Ewing, O. Iliev, R. Lazarov, I. Rybak, J. Willems

An efficient approach for upscaling properties of composite materials with high contrast of coefficients

Keywords: effective heat conductivity, permeability of fractured porous media, numerical upscaling, fibrous insulation materials, metal foams

(16 pages, 2008)

133. S. Gelareh, S. Nickel

New approaches to hub location problems in public transport planning Keywords: integer programming, hub location, transportation, decomposition, heuristic

(25 pages, 2008)

134. G. Thömmes, J. Becker, M. Junk, A. K. Vaikuntam, D. Kehrwald, A. Klar, K. Steiner, A. Wiegmann

A Lattice Boltzmann Method for immiscible multiphase flow simulations using the Level Set Method

Keywords: Lattice Boltzmann method, Level Set method, free surface, multiphase flow (28 pages, 2008

\section{J. Orlik}

Homogenization in elasto-plasticity

Keywords: multiscale structures, asymptotic homogenization, nonlinear energy

(40 pages, 2008)

136. J. Almquist, H. Schmidt, P. Lang, J. Deitmer, M. Jirstrand, D. Prätzel-Wolters, H. Becker

Determination of interaction between MCT1 and CAII via a mathematical and physiological approach

Keywords: mathematical modeling; model reduction: electrophysiology; $\mathrm{pH}$-sensitive microelectrodes; proton antenna

(20 pages, 2008)
137. E. Savenkov, H. Andrä, O. Iliev

An analysis of one regularization approach for solution of pure Neumann problem Keywords: pure Neumann problem, elasticity, regularization, finite element method, condition number (27 pages, 2008)

138. O. Berman, J. Kalcsics, D. Krass, S. Nickel The ordered gradual covering location problem on a network

Keywords: gradual covering, ordered median function, network location

(32 pages, 2008)

139. S. Gelareh, S. Nickel

Multi-period public transport design: A novel model and solution approaches Keywords: Integer programming, hub location, public transport, multi-period planning, heuristics (31 pages, 2008)

140. T. Melo, S. Nickel, F. Saldanha-da-Gama Network design decisions in supply chain planning

Keywords: supply chain design, integer programming models, location models, heuristics

(20 pages, 2008)

141. C. Lautensack, A. Särkkä, J. Freitag K. Schladitz

Anisotropy analysis of pressed point processes

Keywords: estimation of compression, isotropy test nearest neighbour distance, orientation analysis, polar ice, Ripley's K function

(35 pages, 2008)

142. O. Iliev, R. Lazarov, J. Willems

A Graph-Laplacian approach for calculating the effective thermal conductivity of complicated fiber geometries

Keywords: graph laplacian, effective heat conductivity, numerical upscaling, fibrous materials

(14 pages, 2008)

143. J. Linn, T. Stephan, J. Carlsson, R. Bohlin Fast simulation of quasistatic rod deformations for VR applications

Keywords: quasistatic deformations, geometrically exact rod models, variational formulation, energy minimization, finite differences, nonlinear conjugate gradients

(7 pages, 2008)

\section{J. Linn, T. Stephan}

Simulation of quasistatic deformations using discrete rod models

Keywords: quasistatic deformations, geometrically exact rod models, variational formulation, energy minimization, finite differences, nonlinear conjugate gradients

(9 pages, 2008

145. J. Marburger, N. Marheineke, R. Pinnau Adjoint based optimal control using meshless discretizations

Keywords: Mesh-less methods, particle methods, Eulerian-Lagrangian formulation, optimization strategies, adjoint method, hyperbolic equations

(14 pages, 2008

\section{S. Desmettre, J. Gould, A. Szimayer}

Own-company stockholding and work effort preferences of an unconstrained executive Keywords: optimal portfolio choice, executive compensation

(33 pages, 2008) 
147. M. Berger, M. Schröder, K.-H. Küfer A constraint programming approach for the two-dimensional rectangular packing problem with orthogonal orientations

Keywords: rectangular packing, orthogonal orientations non-overlapping constraints, constraint propagation

(13 pages, 2008)

148. K. Schladitz, C. Redenbach, T. Sych, M. Godehardt

Microstructural characterisation of open foams using $3 d$ images

Keywords: virtual material design, image analysis, open foams

(30 pages, 2008)

149. E. Fernández, J. Kalcsics, S. Nickel, R. Ríos-Mercado

A novel territory design model arising in the implementation of the WEEE-Directive Keywords: heuristics, optimization, logistics, recycling (28 pages, 2008)

150. H. Lang, J. Linn

Lagrangian field theory in space-time for geometrically exact Cosserat rods Keywords: Cosserat rods, geometrically exact rods, small strain, large deformation, deformable bodies, Lagrangian field theory, variational calculus (19 pages, 2009)

151. K. Dreßler, M. Speckert, R. Müller, Ch. Weber

Customer loads correlation in truck engineering

Keywords: Customer distribution, safety critical components, quantile estimation, Monte-Carlo methods (11 pages, 2009)

152. H. Lang, K. Dreßler

An improved multiaxial stress-strain correction model for elastic FE postprocessing Keywords: Jiang's model of elastoplasticity, stress-strain correction, parameter identification, automatic differentiation, least-squares optimization, Coleman-Li algorithm

(6 pages, 2009)

153. J. Kalcsics, S. Nickel, M. Schröder A generic geometric approach to territory design and districting

Keywords: Territory design, districting, combinatorial optimization, heuristics, computational geometry (32 pages, 2009)

154. Th. Fütterer, A. Klar, R. Wegener An energy conserving numerical scheme for the dynamics of hyperelastic rods

Keywords: Cosserat rod, hyperealstic, energy conservation, finite differences

(16 pages, 2009)

155. A. Wiegmann, L. Cheng, E. Glatt, O. Iliev, S. Rief

Design of pleated filters by computer simulations

Keywords: Solid-gas separation, solid-liquid separation, pleated filter, design, simulation

(21 pages, 2009)

156. A. Klar, N. Marheineke, R. Wegener Hierarchy of mathematical models for production processes of technical textiles
Keywords: Fiber-fluid interaction, slender-body theory, turbulence modeling, model reduction, stochastic differential equations, Fokker-Planck equation, asymptotic expansions, parameter identification

(21 pages, 2009)

157. E. Glatt, S. Rief, A. Wiegmann, M. Knefel, E. Wegenke

Structure and pressure drop of real and virtual metal wire meshes

Keywords: metal wire mesh, structure simulation, model calibration, CFD simulation, pressure loss (7 pages, 2009)

\section{S. Kruse, M. Mülle}

Pricing American call options under the assumption of stochastic dividends - An application of the Korn-Rogers model Keywords: option pricing, American options, dividends, dividend discount model, Black-Scholes model (22 pages, 2009)

159. H. Lang, J. Linn, M. Arnold

Multibody dynamics simulation of geometrically exact Cosserat rods

Keywords: flexible multibody dynamics, large deformations, finite rotations, constrained mechanical systems, structural dynamics

(20 pages, 2009)

160. P. Jung, S. Leyendecker, J. Linn, M. Ortiz Discrete Lagrangian mechanics and geometrically exact Cosserat rods

Keywords: special Cosserat rods, Lagrangian mechanics, Noether's theorem, discrete mechanics, frame-indifference, holonomic constraints

(14 pages, 2009)

161. M. Burger, K. Dreßler, A. Marquardt, M. Speckert

Calculating invariant loads for system simulation in vehicle engineering

Keywords: iterative learning control, optimal control

theory, differential algebraic equations (DAEs)

(18 pages, 2009)

162. M. Speckert, N. Ruf, K. Dreßler Undesired drift of multibody models excited by measured accelerations or forces Keywords: multibody simulation, full vehicle model, force-based simulation, drift due to noise

(19 pages, 2009)

163. A. Streit, K. Dreßler, M. Speckert, J. Lichter, T. Zenner, P. Bach

Anwendung statistischer Methoden zur Erstellung von Nutzungsprofilen für die Auslegung von Mobilbaggern

Keywords: Nutzungsvielfalt, Kundenbeanspruchung, Bemessungsgrundlagen

(13 pages, 2009)

164. I. Correia, S. Nickel, F. Saldanha-da-Gama The capacitated single-allocation hub location problem revisited: A note on a classical formulation

Keywords: Capacitated Hub Location, MIP formulations (10 pages, 2009)

165. F. Yaneva, T. Grebe, A. Scherrer

An alternative view on global radiotherapy optimization problems

Keywords: radiotherapy planning, path-connected sublevelsets, modified gradient projection method, improving and feasible directions

(14 pages, 2009)
166. J. I. Serna, M. Monz, K.-H. Küfer, C. Thieke Trade-off bounds and their effect in multicriteria IMRT planning

Keywords: trade-off bounds, multi-criteria optimization, IMRT, Pareto surface

(15 pages, 2009)

167. W. Arne, N. Marheineke, A. Meister, R. Wegener

Numerical analysis of Cosserat rod and string models for viscous jets in rotational spinning processes

Keywords: Rotational spinning process, curved viscous fibers, asymptotic Cosserat models, boundary value problem, existence of numerical solutions

(18 pages, 2009)

168. T. Melo, S. Nickel, F. Saldanha-da-Gama An LP-rounding heuristic to solve a multiperiod facility relocation problem

Keywords: supply chain design, heuristic, linear programming, rounding

(37 pages, 2009)

169. I. Correia, S. Nickel, F. Saldanha-da-Gama Single-allocation hub location problems with capacity choices

Keywords: hub location, capacity decisions, MILP formulations

(27 pages, 2009)

170. S. Acar, K. Natcheva-Acar A guide on the implementation of the Heath-Jarrow-Morton Two-Factor Gaussian Short Rate Model (HJM-G2++)

Keywords: short rate model, two factor Gaussian, G2++, option pricing, calibration

(30 pages, 2009)

171. A. Szimayer, G. Dimitroff, S. Lorenz A parsimonious multi-asset Heston model: calibration and derivative pricing Keywords: Heston model, multi-asset, option pricing, calibration, correlation

(28 pages, 2009)

172. N. Marheineke, R. Wegener Modeling and validation of a stochastic drag for fibers in turbulent flows Keywords: fiber-fluid interactions, long slender fibers, turbulence modelling, aerodynamic drag, dimensional analysis, data interpolation, stochastic partial differential algebraic equation, numerical simulations, experimental validations

(19 pages, 2009)

173. S. Nickel, M. Schröder, J. Steeg Planning for home health care services Keywords: home health care, route planning, metaheuristics, constraint programming

(23 pages, 2009)

174. G. Dimitroff, A. Szimayer, A. Wagner Quanto option pricing in the parsimonious Heston model

Keywords: Heston model, multi asset, quanto options, option pricing

(14 pages, 2009) 174. G. Dimitroff, A. Szimayer, A. Wagner

175. S. Herkt, K. Dreßler, R. Pinnau

Model reduction of nonlinear problems in structural mechanics

Keywords: flexible bodies, FEM, nonlinear model reduc tion, $P O D$

(13 pages, 2009) 
176. M. K. Ahmad, S. Didas, J. Iqbal

Using the Sharp Operator for edge detection and nonlinear diffusion

Keywords: maximal function, sharp function, image processing, edge detection, nonlinear diffusion

(17 pages, 2009)

177. M. Speckert, N. Ruf, K. Dreßler, R. Müller, C. Weber, S. Weihe

Ein neuer Ansatz zur Ermittlung von Erprobungslasten für sicherheitsrelevante Bauteile

Keywords: sicherheitsrelevante Bauteile, Kundenbeanspruchung, Festigkeitsverteilung, Ausfallwahrscheinlichkeit, Konfidenz, statistische Unsicherheit, Sicherheitsfaktoren

(16 pages, 2009)

\section{J. Jegorovs}

Wave based method: new applicability areas Keywords: Elliptic boundary value problems, inhomogeneous Helmholtz type differential equations in bounded domains, numerical methods, wave based method, uniform B-splines

(10 pages, 2009)

179. H. Lang, M. Arnold

Numerical aspects in the dynamic simulation of geometrically exact rods Keywords: Kirchhoff and Cosserat rods, geometrically exact rods, deformable bodies, multibody dynamics, artial differential algebraic equations, method of lines, time integration

(21 pages, 2009)

180. H. Lang

Comparison of quaternionic and rotationfree null space formalisms for multibody dynamics

Keywords: Parametrisation of rotations, differentialalgebraic equations, multibody dynamics, constrained mechanical systems, Lagrangian mechanics

(40 pages, 2010)

181. S. Nickel, F. Saldanha-da-Gama, H.-P. Ziegler Stochastic programming approaches for risk aware supply chain network design problems Keywords: Supply Chain Management, multi-stage stochastic programming, financial decisions, risk (37 pages, 2010)

\section{P. Ruckdeschel, N. Horbenko}

Robustness properties of estimators in generalized Pareto Models

Keywords: global robustness, local robustness, finite sample breakdown point, generalized Pareto distribution (58 pages, 2010)

\section{P. Jung, S. Leyendecker, J. Linn, M. Ortiz}

A discrete mechanics approach to Cosserat rod theory - Part 1: static equilibria

Keywords: Special Cosserat rods; Lagrangian mechanics; Noether's theorem; discrete mechanics; frameindifference; holonomic constraints; variational formulation

(35 pages, 2010)

184. R. Eymard, G. Printsypar

A proof of convergence of a finite volume scheme for modified steady Richards' equation describing transport processes in the pressing section of a paper machine Keywords: flow in porous media, steady Richards' equation, finite volume methods, convergence of approximate solution

(14 pages, 2010)

185. P. Ruckdeschel

\section{Optimally Robust Kalman Filtering}

Keywords: robustness, Kalman Filter, innovation outlier, additive outlier

(42 pages, 2010)

186. S. Repke, N. Marheineke, R. Pinnau On adjoint-based optimization of a free surface Stokes flow

Keywords: film casting process, thin films, free surface Stokes flow, optimal control, Lagrange formalism (13 pages, 2010)

187. O. Iliev, R. Lazarov, J. Willems

Variational multiscale Finite Element Method for flows in highly porous media Keywords: numerical upscaling, flow in heterogeneous porous media, Brinkman equations, Darcy's law, subgrid approximation, discontinuous Galerkin mixed FEM (21 pages, 2010)

\section{S. Desmettre, A. Szimayer}

Work effort, consumption, and portfolio selection: When the occupational choice matters

Keywords: portfolio choice, work effort, consumption, occupational choice

(34 pages, 2010)

189. O. Iliev, Z. Lakdawala, V. Starikovicius On a numerical subgrid upscaling algorithm for Stokes-Brinkman equations

Keywords: Stokes-Brinkman equations, subgrid approach, multiscale problems, numerical upscaling (27 pages, 2010)

190. A. Latz, J. Zausch, O. Iliev

Modeling of species and charge transport in Li-Ion Batteries based on non-equilibrium thermodynamics

Keywords: lithium-ion battery, battery modeling, electrochemical simulation, concentrated electrolyte, ion transpor

(8 pages, 2010)

191. P. Popov, Y. Vutov, S. Margenov, O. Iliev Finite volume discretization of equations describing nonlinear diffusion in Li-Ion batteries

Keywords: nonlinear diffusion, finite volume discretization, Newton method, Li-lon batteries

(9 pages, 2010)

192. W. Arne, N. Marheineke, R. Wegener Asymptotic transition from Cosserat rod to string models for curved viscous inertial jets

Keywords: rotational spinning processes; inertial and viscous-inertial fiber regimes; asymptotic limits; slenderbody theory; boundary value problems

(23 pages, 2010)

193. L. Engelhardt, M. Burger, G. Bitsch Real-time simulation of multibody-systems for on-board applications

Keywords: multibody system simulation, real-time simulation, on-board simulation, Rosenbrock methods (10 pages, 2010)

\section{M. Burger, M. Speckert, K. Dreßler} Optimal control methods for the calculation of invariant excitation signals for multibody systems

Keywords: optimal control, optimization, mbs simulation, invariant excitation

(9 pages, 2010)
195. A Latz, J. Zausch

Thermodynamic consistent transport theory of Li-lon batteries

Keywords: Li-lon batteries, nonequilibrium thermodynamics, thermal transport, modeling

(18 pages, 2010)

\section{S. Desmettre}

Optimal investment for executive stockholders with exponential utility Keywords: portfolio choice, executive stockholder work effort, exponential utility

(24 pages, 2010)

197. W. Arne, N. Marheineke, J. Schnebele, R. Wegener

Fluid-fiber-interactions in rotational spinning process of glass wool production Keywords: Rotational spinning process, viscous thermal jets, fluid-fiber-interactions, two-way coupling, slenderbody theory, Cosserat rods, drag models, boundary value problem, continuation method

(20 pages, 2010)

198. A. Klar, J. Maringer, R. Wegener

A 3d model for fiber lay-down in nonwoven production processes

Keywords: fiber dynamics, Fokker-Planck equations, diffusion limits

(15 pages, 2010)

199. Ch. Erlwein, M. Müller

A regime-switching regression model for hedge funds

Keywords: switching regression model, Hedge funds, optimal parameter estimation, filtering

(26 pages, 2011)

200. M. Dalheimer

Power to the people - Das Stromnetz der Zukunft

Keywords: Smart Grid, Stromnetz, Erneuerbare Energien, Demand-Side Management

(27 pages, 2011)

201. D. Stahl, J. Hauth

PF-MPC: Particle Filter-Model Predictive Control

Keywords: Model Predictive Control, Particle Filter, CSTR, Inverted Pendulum, Nonlinear Systems, Sequential Monte Carlo

(40 pages, 2011)

\section{G. Dimitroff, J. de Kock}

Calibrating and completing the volatility cube in the SABR Model

Keywords: stochastic volatility, SABR, volatility cube, swaption

(12 pages, 2011)

203. J.-P. Kreiss, T. Zangmeister

Quantification of the effectiveness of a safety function in passenger vehicles on the basis of real-world accident data Keywords: logistic regression, safety function, realworld accident data, statistical modeling (23 pages, 2011)

204. P. Ruckdeschel, T. Sayer, A. Szimayer Pricing American options in the Heston model: a close look on incorporating correlation

Keywords: Heston model, American options, moment matching, correlation, tree method

(30 pages, 2011) 
M. Schröder

Modeling profit sharing in combinatorial exchanges by network flows

Keywords: Algorithmic game theory, profit sharing, combinatorial exchange, network flows, budget balance, core

(17 pages, 2011)

206. O. lliev, G. Printsypar, S. Rief

A one-dimensional model of the pressing section of a paper machine including $d y$ namic capillary effects

Keywords: steady modified Richards' equation, finite volume method, dynamic capillary pressure, pressing section of a paper machine

(29 pages, 2011)

207. I. Vecchio, K. Schladitz, M. Godehardt,

$$
\text { M. J. Heneka }
$$

Geometric characterization of particles in $3 d$ with an application to technical cleanliness Keywords: intrinsic volumes, isoperimetric shape factors, bounding box, elongation, geodesic distance, techni-

cal cleanliness

(21 pages, 2011)

208. M. Burger, K. Dreßler, M. Speckert Invariant input loads for full vehicle multibody system simulation

Keywords: multibody systems, full-vehicle simulation, optimal control

(8 pages, 2011)

209. H. Lang, J. Linn, M. Arnold

Multibody dynamics simulation of geometrically exact Cosserat rods

Keywords: flexible multibody dynamics, large deformations, finite rotations, constrained mechanical systems, structural dynamics

(28 pages, 2011)

\section{G. Printsypar, R. Ciegis}

On convergence of a discrete problem describing transport processes in the pressing section of a paper machine including dynamic capillary effects: one-dimensional case Keywords: saturated and unsaturated fluid flow in porous media, Richards' approach, dynamic capillary pressure, finite volume methods, convergence of approximate solution

(24 pages, 2011)

211. O. Iliev, G. Printsypar, S. Rief

A two-cimensional model of the pressing section of a paper machine including $d y$ namic capillary effects

Keywords: two-phase flow in porous media, steady modified Richards' equation, finite volume method, $d y$ namic capillary pressure, pressing section of a paper machine, multipoint flux approximation

(44 pages, 2012)

\section{A. Buck, O. lliev, H. Andrä}

Multiscale finite element coarse spaces for the analysis of linear elastic composites

Keywords: linear elasticity, domain decomposition, multiscale finite elements, robust coarse spaces, rigid body modes, discontinuous coefficients

(31 pages, 2012)

\section{A. Wagner}

Residual demand modeling and application to electricity pricing

Keywords: residual demand modeling, renewable infeed, wind infeed, solar infeed, electricity demand, German power market, merit-ordereect

(28 pages, 2012) 
